NBER WORKING PAPER SERIES

\title{
REDISTRIBUTION BY INSURANCE MARKET REGULATION: ANALYZING A BAN ON GENDER-BASED RETIREMENT ANNUITIES
}

\author{
Amy Finkelstein \\ James Poterba \\ Casey Rothschild \\ Working Paper 12205 \\ http://www.nber.org/papers/w12205
NATIONAL BUREAU OF ECONOMIC RESEARCH
1050 Massachusetts Avenue
Cambridge, MA 02138
April 2006

\begin{abstract}
We are grateful to Jeff Brown, Pierre-Andre Chiappori, Keith Crocker, Peter Diamond, Liran Einav, Mikhail Golosov, Robert Gibbons, Kenneth Judd, Whitney Newey, Bernard Salanie, and participants at the NBER Insurance Meeting, the Stanford Institute for Theoretical Economics, and the Econometric Society Annual Meeting for helpful discussions, to Luke Joyner and Nelson Elhage for research assistance, and to the National Institute of Aging and the National Science Foundation (Poterba and Rothschild) for research support. The views expressed herein are those of the author(s) and do not necessarily reflect the views of the National Bureau of Economic Research.

(C)2006 by Amy Finkelstein, James Poterba and Casey Rothschild. All rights reserved. Short sections of text, not to exceed two paragraphs, may be quoted without explicit permission provided that full credit, including (C) notice, is given to the source.
\end{abstract}


Redistribution by Insurance Market Regulation: Analyzing a Ban on Gender-Based Retirement Annuities

Amy Finkelstein, James Poterba and Casey Rothschild

NBER Working Paper No. 12205

April 2006

JEL No. D82, H55, L51

\begin{abstract}
$\underline{\text { ABSTRACT }}$
This paper shows how models of insurance markets with asymmetric information can be calibrated and solved to yield quantitative estimates of the consequences of government regulation. We estimate the impact of restricting gender-based pricing in the United Kingdom retirement annuity market, a market in which individuals are required to annuitize tax-preferred retirement savings but are allowed considerable choice over the annuity contract they purchase. After calibrating a lifecycle utility model and estimating a model of annuitant mortality that allows for unobserved heterogeneity, we solve for the range of equilibrium contract structures with and without gender-based pricing. Eliminating gender-based pricing is generally thought to redistribute resources from men to women, since women have longer life expectancies. We find that allowing insurers to offer a menu of contracts may reduce the amount of redistribution from men to women associated with gender-blind pricing requirements to half the level that would occur if insurers were required to sell a single pre-specified policy. The latter "one policy" scenario corresponds loosely to settings in which governments provide compulsory annuities as part of their Social Security program. Our findings suggest that recognizing the endogenous structure of insurance contracts is important for analyzing the economic effects of insurance market regulations. More generally, our results suggest that theoretical models of insurance market equilibrium can be used for quantitative policy analysis, not simply to derive qualitative findings.
\end{abstract}

Amy Finkelstein

Department of Economics

MIT E52 262F

50 Memorial Drive

Cambridge MA 02142

and NBER

afink@mit.edu

James M. Poterba

Department of Economics

MIT, E52-350

50 Memorial Drive

Cambridge, MA 02142-1347

and NBER

poterba@mit.edu
Casey Rothschild

MIT Department of Economics

Office Number E51-390

E52, Room 391

Cambridge MA 02142-1347

caseyr@mit.edu 
Restrictions on the use of characteristics such as race or gender in pricing are ubiquitous in private insurance markets. These restrictions are likely to become even more important as the advent of genetic tests enriches the information set that insurers might use to price life and health insurance policies. Several theoretical studies, including Hoy (1982) and Crocker and Snow (1986), have analyzed this form of regulation and shown qualitatively that they have unavoidable negative efficiency consequences. Empirical work such as Buchmueller and DiNardo (2002) and Simon (forthcoming) has confirmed the existence of such efficiency costs by documenting declines in insurance coverage when characteristicbased pricing is banned in health insurance markets. However, there have been few if any attempts to develop quantitative estimates of the efficiency costs or the distributional impacts of restrictions on characteristic-based pricing. One of the few studies in this vein is Blackmon and Zeckhauser's (1991) analysis of automobile insurance regulation. It frames questions similar to the ones we study but does not analyze how the structure of insurance contracts may respond to regulatory restrictions or how this affects distributional or efficiency effects.

In this paper, we take a first step toward developing quantitative estimates of the effects of endogenous contract responses to insurance market regulation. We extend existing theoretical models and adapt them to provide quantitative estimates of both the efficiency and redistributive effects of a unisex pricing requirement for pension annuities. Restrictions on characteristic-based pricing are usually thought to transfer resources from individuals in lower-risk categories to those with greater risks. Women are longer-lived than men, so unisex pricing restrictions in the pension marketplace redistribute from men to women. Some might argue for such policies on redistributive grounds, since elderly women have higher poverty rates than elderly men. Viewed from the ex-interim perspective once individual characteristics are known, the transfers from men to women generate redistribution akin to the redistribution associated with uniform pricing regulations in industries such as telephone and electricity distribution, where individuals have different costs of service. Posner (1971) labeled such redistribution "taxation by regulation." Alternatively, from an ex-ante perspective before individual characteristics are known, the 
redistribution may be viewed as a form of insurance against drawing a high-cost characteristic, in this case being female, as in Hirshleifer (1971).

In addition to providing a tractable setting for illustrating our techniques, the pension annuity market is an interesting setting in its own right because of its size, its importance for retiree welfare, and the salience of unisex pricing regulations in this market. Private annuity arrangements, typically the payouts from defined benefit pension plans, represent an important source of retirement income for many elderly households. Employers in the United States were once free to offer different pension annuity payouts to men and women, but litigation in the 1970s and early 1980s eliminated this practice. The European Union is currently debating regulatory reforms that may eliminate gender-based pricing in insurance markets, including pension annuity markets. Our analysis may also have broader implications for the design and regulation of annuitized payout structures associated with defined contribution Social Security systems.

We are not aware of any previous attempts to calibrate and solve stylized theoretical models of insurance market equilibria. Doing so requires adapting these models to account for a number of features that are observed in actual insurance markets. One that has quantitatively important implications is our relaxation of the assumption that individuals have no recourse to an informal, if inefficient, substitute for insurance. Our analysis recognizes that individuals may save against the contingency of a long life, and that insurance companies many not observe savings by their policyholders. If we do not allow for unobservable savings, the informational asymmetries created by a ban on gender categorization may have neither efficiency nor distributional effects.

We focus on the retirement annuity market in the United Kingdom, where we have obtained a rich micro-data set that facilitates our calibration. A critical feature of this market is that workers who have accumulated tax-preferred retirement savings must purchase an annuity. They cannot choose whether or not to participate in the annuity market, which eliminates one margin on which unisex pricing regulations could potentially affect individual behavior. Participants do have substantial flexibility with regard to contract choice. Empirical evidence, such as that presented in Finkelstein and Poterba (2004), suggests that this choice is affected by private information about risk type. 
Our main finding is that recognizing the endogenous response in the structure of insurance contracts when regulations change may reduce by as much as fifty percent the amount of redistribution away from men and toward women that would be associated with a ban on gender-based annuity pricing in a fully compulsory annuity market with no scope for this response; this latter setting in which insurers are required to sell a single pre-specified policy loosely corresponds to settings in which governments provide compulsory annuities as part of their Social Security program. Our findings highlight the importance of recognizing the endogenous structure of insurance contracts when analyzing the economic effects of insurance market regulation, and they indicate that theoretical models of insurance market equilibrium can be adapted to offer quantitative predictions on regulatory issues. Even accounting for the endogenous contract response, however, we find that a ban on gender-based pricing in the U.K. retirement annuity market would have substantial distributional consequences, in most cases redistributing at least three percent of retirement wealth from men to women. We also estimate that the efficiency costs associated with this redistribution would be very small. However, since individuals do not have a choice of whether or not to participate in this market, our estimates of the efficiency costs of unisex pricing restrictions are likely to substantially underestimate the cost of such restrictions in voluntary annuity markets.

Our analysis is divided into six sections. The first briefly reviews the qualitative impact of uniform pricing requirements in insurance markets with asymmetric information. Based on the assumption that annuity markets operate in a constrained-efficient manner, section two develops a model of the range of possible contracts offered and purchased in equilibrium. It also describes results concerning equilibrium contract structure and our algorithm for solving for these contracts. It is supplemented by a technical appendix. In the third section we calibrate the model and describe our estimates of a two-type mixture model for mortality rates. Section four describes the measures that we use for evaluating the efficiency and distributional effects of policy interventions in insurance markets. The fifth section presents our quantitative results. We describe the range of possible distributional and efficiency effects of restrictions on gender based pricing under different assumptions concerning the constraints on consumers and 
producers. A brief conclusion discusses how our results bear on a number of ongoing policy debates and describes possible generalizations of our approach to other insurance markets.

\section{A Framework for Analyzing Regulation in Insurance Markets}

This section reviews the qualitative efficiency and distributional effects of a ban on categorization in a standard two-state, two-type model of competitive insurance markets with asymmetric information. This framework considers two distinct types of individuals who are indistinguishable to an insurance company but who face different risks of a loss. Individuals can insure themselves against loss by purchasing a single insurance contract from firms in a competitive market.

\subsection{Qualitative Analysis of Banning Categorization in the "Perfect Categorization" Case}

There is little consensus concerning the proper equilibrium concept for insurance markets with asymmetric information, as Hellwig (1987) explains. We therefore follow the approach taken by Crocker and Snow (1986) in their analysis of the efficiency impacts of bans on categorization and focus on

constrained efficient outcomes. In focusing on these outcomes, we implicitly assume that the private market achieves efficient outcomes, within the scope of their ability to do so, without explicitly modeling equilibrium behavior. We note, however, that the so-called Miyazaki (1977)-Wilson (1977)-Spence (1978) (hereafter MWS) equilibrium provides an example of a model of equilibrium behavior that results in a constrained efficient outcome. We will describe this MWS outcome in more detail after characterizing the entire efficient frontier, as it will play an important role in our analysis.

To characterize the frontier, denote the high risk and low risk types by $\mathrm{H}$ and $\mathrm{L}$, respectively. Let $V^{i}(A)$ denote the indirect utility achieved by type $i$ when she has purchased insurance contract $A$, and let $\Pi^{i}(A)$ denote the expected profits a firm earns by selling contract $A$ to type $i$. With this notation, points on the Pareto frontier solve the following program, where $\lambda$ is the proportion of $\mathrm{H}$ types: 
$\max _{A^{L}, A^{H}} V^{L}\left(A^{L}\right)$

subject to

$$
\begin{aligned}
& \left(I C_{H}\right) V^{H}\left(A^{H}\right) \geq V^{H}\left(A^{L}\right) \\
& \left(I C_{L}\right) V^{L}\left(A^{L}\right) \geq V^{L}\left(A^{H}\right) \\
& (M U) V^{H}\left(A^{H}\right) \geq \bar{V}^{H} \\
& (B C)(1-\lambda) \Pi^{L}\left(A^{L}\right)+\lambda \Pi^{H}\left(A^{H}\right) \geq 0,
\end{aligned}
$$

where $\left(\mathrm{IC}_{\mathrm{i}}\right)$ is the incentive compatibility constraint stating that $i$ types must be willing to choose the contract designed for them, $(\mathrm{BC})$ is a budget constraint that requires that on average policies break even, and (MU) is a minimum utility constraint for the $\mathrm{H}$ types.

Crocker and Snow (1985) characterize this constrained Pareto frontier in the standard two period (one-accident) setting by varying the Lagrange multiplier on constraint (MU) in (1). In Figure 1, we characterize the frontier in the same two-period setting by varying the value of $\bar{V}^{H}$. Insurance contracts can be written as state-contingent consumption vectors $A=\left(a_{0}, a_{1}\right)$, where the subscript 0 refers to the "no accident" state and the subscript 1 refers to the "accident" state. Insurance providers supply these consumption promises $A$ in exchange for a buyer's state-contingent endowment wealth vector $W=\left(w_{0}, w_{0}-\ell\right) . H$ types have a higher probability of experiencing state 1 and the types are otherwise identical expected utility maximizers with a strictly concave utility function.

For low values of $\bar{V}^{H}$, (MU) may be slack. For example, if $\bar{V}^{H}=\max _{\left\{A: \Pi^{H}(A)=0\right\}} V^{H}(A)$ so that (MU) says that $\mathrm{H}$ types have to be at least as well off as they would be with their full insurance actuarially fair consumption point, then (MU) will be slack precisely when the Rothschild and Stiglitz (1976) equilibrium either fails to exist or exists but fails to be constrained efficient. Such a situation is depicted at point M in Figure 1. At point M, L types consume the constrained efficient allocation that is best for them; this corresponds to the MWS equilibrium. Figure 1 shows that even this best-for-L allocation can involve positive cross subsidies from the Ltypes to the H types. 
The dark curve connecting points $\mathrm{M}$ and $\mathrm{F}$ in Figure 1 depicts a portion of the locus of the L type consumption points that correspond to constrained Pareto optimal outcomes. The point labeled $\mathrm{F}$ is the unique "pooling" outcome on the frontier - i.e., the unique constrained efficient outcome with $A^{L}=A^{H}$. It is on the 45-degree line and therefore provides full insurance. Point F involves substantially larger cross subsidies from $\mathrm{L}$ types to $\mathrm{H}$ types than does $\mathrm{M}$. There are additional constrained efficient outcomes not depicted in Figure 1 which involve even larger cross subsidies from $L$ type to $H$ types than those at point F. Such outcomes involve the L types being fully insured and the $\mathrm{H}$ types being overinsured, which Crocker and Snow (1985) note is a feature absent from standard models of equilibrium in insurance markets. As a result, we do not consider this portion of the frontier. The set of outcomes we consider is thus captured in the region of the frontier bounded by F and M; we do not try to select any particular constrained efficient outcome from this set.

Because (1) permits - and, as in the case of Figure 1, may even require - the market to implement a contract pair involving cross subsidies across types, bans in characteristic-based pricing can have both distributional and efficiency consequences. This is illustrated in Figure 2, which depicts a constrained efficient pair of contracts. When type is observable and can be used in pricing, the competitive equilibrium will provide each type with her actuarially fair full insurance contract. In Figure $2, A^{H^{*}}$ and $A^{L^{*}}$ depict the full insurance actuarially fair contracts that we assume emerge when type is observable and can be contracted upon. Consumption for each type is independent of the realized state of nature.

When type-based pricing is banned, our assumption is that the market implements a pair of contracts, labeled $A^{H}$ and $A^{L}$, which is constrained efficient given the informational restrictions of the ban. Note that as depicted this contract pair involves positive cross subsidies between types. As a result, $\mathrm{H}$ types are better off when categorization is banned, and L types are worse off. This illustrates how a ban on categorical-based pricing may have distributional consequences. The ban is efficiency reducing in this example as well. Since type is, in fact, observable, it is in principle possible to make L types as well off as with $A^{L}$ via contract $A^{L}$, which is also actuarially cheaper to provide to the $\mathrm{L}$ types. 


\subsection{Residual Private Information}

The foregoing discussion assumes that type is observable. A ban on characteristic-based pricing therefore moves the economy from perfect information to imperfect information. In practice, information such as gender or the outcome of a genetic test may be related to risk type, but even conditional on this information, insurers are unlikely to be able to completely determine the risk of potential policy buyers. The relevant comparison is therefore between imperfect information and more imperfect information.

Our study builds on previous analyses of bans on characteristic-based pricing, such as Hoy (1982) and Crocker and Snow (1986), which use the most parsimonious model that can capture the presence of residual uncertainty. There are still two risk types, but risk type is not directly observable. Instead, insurers only observe a signal that is correlated with risk type. There are two possible signals, $X$ and $Y$. We henceforth refer to individuals as falling in category $X$ or category $Y$. A fraction $\lambda_{k}$ of category $k$ individuals are high risk types, with $0<\lambda_{X}<\lambda_{Y}<1$. Thus, category $Y$ is the high-risk category, but there are still low-risk types within that category. We denote by $\theta$ the fraction of category $Y$ individuals in the population.

For our analysis, we continue to assume that markets will operate in a constrained efficient manner given the information which is both available and legal for use in pricing. When characteristic-based pricing is permitted, we further assume that the market will not implement contracts involving crosssubsidies across observable categories, just as we did in Figure 2 by assuming that the contracts $A^{H^{*}}$ and $A^{L^{*}}$ emerge when type-based pricing was allowed. A ban on categorical pricing in this imperfectinformation setting will have the same qualitative effects as it does in the perfect information setting described above.

\section{Modeling Restrictions on Gender-Based Pricing in the U.K. Pension Annuity Market}

The preceding discussion illustrates the qualitative impact of a ban on categorization on efficiency and redistribution. To develop quantitative estimates, we consider a particular ban on categorization in a 
particular market, namely the imposition of unisex pricing requirements in the U.K. annuity market. Individuals in the United Kingdom with defined contribution private pension plans that have benefited from tax deferral on investment income — the analogues of IRAs and 401(k)'s in the United States—face compulsory annuitization requirements for a substantial share of the balance accumulated by retirement. In 1998, data from the Association of British Insurers (1999) suggest that annual annuity payments in this market totaled $£ 5.4$ billion.

Although annuitization is compulsory, annuitants in the U.K. retirement annuity market have some scope for self-selection across contract choice. Finkelstein and Poterba $(2004,2006)$ find that such selfselection appears to reflect private information about mortality risk. Note that, from the perspective of an insurance company, high-risk annuitants are those who are likely to live longer than the characteristics used in pricing, such as age and gender, would suggest. There are currently no regulations in the U.K. annuity market limiting the characteristics used in pricing annuities. In practice, annuities are priced almost exclusively on age at purchase and gender. Several small firms entered the annuity market after the end of our sample with discounted annuities for heavy smokers, but those products were not available during the period that we study.

While the two-state model discussed above suffices for the understanding the qualitative impacts of interventions that ban categorical pricing, it is too stylized to plausibly measure the quantitative impact of regulatory interventions. Since an individual can live for many years after the purchase of their annuity, we extend the analysis to 35 periods. Boadway and Townley (1988) is the only other contract theoretic model we have found that includes more than three periods in an analysis of an annuity market with asymmetric information, but the contracts under consideration have a particular and restrictive form that we relax. This extension to many periods is essential for a plausible calibration.

Our baseline model also allows for unobservable savings. Eichenbaum and Peled (1987), Brunner and Pech (2005), and others note that allowing annuitants to engage in unobservable saving limits the ability of insurers to screen different types of observationally equivalent annuity buyers. In our context, we show that when insurance companies can observe savings, the informational asymmetries created by a ban on 
gender categorization can have neither efficiency nor distributional consequences. The process of deriving and solving the model, which we discuss below, provides insight into why accounting for unobservable savings is critical for any plausible calibration. It also demonstrates why this extension makes the model substantially more difficult to solve. We show that it is nevertheless possible to solve for the contracts on the constrained Pareto frontier, and we sketch our computational algorithm.

\subsection{Defining Annuity Market Outcomes}

Our model applies to any number of periods $t=0, \cdots, N$, where we interpret $t$ as the number of years after retirement, which we take to be at age $R=65$. In practice, we take $N=35$, thereby assuming individuals do not live past age 100 . To capture the compulsory purchase requirement, we assume that individuals must use their retirement wealth $W$ to purchase an annuity. They exponentially discount the future at rate $\delta=1 / 1+r$ per year, where $r$ is the interest rate, and by their (cumulative) probability $S_{t}$ of living to a given age $\mathrm{R}+t$. The two risk types, $\mathrm{H}$ and $\mathrm{L}$, differ only in their survival probabilities. There is a continuum of individuals, with a fraction $\lambda$ of $\mathrm{H}$ types. We assume $S_{t+1}^{H} / s_{t}^{H}>S_{t+1}^{L} / S_{t}^{L}$ for each $\mathrm{t}$; in other words, the ratio of the cumulative survival probabilities of the two types must be monotone in age. This is satisfied if the higher longevity type has a lower mortality hazard at every age.

The direct utility of a consumption stream $\Gamma=\left(c_{0}, \cdots, c_{N}\right)$ for type $\sigma$ is given by:

$$
U^{\sigma}\left(c_{0}, \cdots, c_{N}\right)=\sum_{t=0}^{N} \delta^{t} S_{t}^{\sigma} u\left(c_{t}\right)=\sum_{t=0}^{N} \delta^{t} S_{t}^{\sigma} \frac{c_{t}^{1-\gamma}}{1-\gamma}
$$

where $\gamma$ is the risk-aversion parameter. Annuity streams, which are denoted by $A$, specify a lifecontingent payment $a_{t}$ in each of the $N+1$ periods. In our baseline model, we impose no structure on the annuity payments $a_{t}$; we later restrict the time profile of possible annuity payments.

Individual savings earn an interest rate $r$. Individuals have no bequest motive, and they cannot borrow against their annuity. This means that individuals with an annuity stream $A$ can obtain any consumption 
stream that satisfies $\Gamma \in F(A) \equiv\left\{\Gamma \mid \sum_{0}^{t} \delta^{s} c_{s} \leq \sum_{0}^{t} \delta^{s} a_{s} \forall t\right\}$. This induces indirect utility functions and type-specific actuarial cost functions

(4) $V^{\sigma}(A)=\max _{\Gamma \in F(A)} U^{\sigma}(\Gamma)$,

and

(5) $C^{\sigma}(A) \equiv \sum_{0}^{N} \delta^{n} S_{t}^{\sigma} a_{t}$

Because individuals discount the future at the rate of interest, "full insurance" annuities have level real payouts. Let $\bar{V}^{\sigma}(X)$ denote the utility that type $\sigma$ gets by consuming the full insurance annuity $\bar{A}$ with $C^{\sigma}(\bar{A})=X$. Let $\overline{\bar{A}}^{\lambda}$ denote the pooled-fair full insurance annuity - i.e., the full insurance annuity satisfying $\lambda C^{H}\left(\overline{\bar{A}}^{\lambda}\right)+(1-\lambda) C^{L}\left(\overline{\bar{A}}^{\lambda}\right)=W$. In a constrained efficient market, the two risk types purchase a pair of annuities $A^{H}$ and $A^{L}$ that solve:

$$
\begin{aligned}
& \max _{A^{L}, A^{H}} V^{L}\left(A^{L}\right) \\
& \quad \text { subject to } \\
& \left(I C_{H}\right) V^{H}\left(A^{H}\right) \geq V^{H}\left(A^{L}\right) \\
& \left(I C_{L}\right) V^{L}\left(A^{L}\right) \geq V^{L}\left(A^{H}\right) \\
& (M U) V^{H}\left(A^{H}\right) \geq \bar{V}^{H} \\
& (B C)(1-\lambda) C^{L}\left(A^{L}\right)+\lambda C^{H}\left(A^{H}\right) \leq W
\end{aligned}
$$

for some $\bar{V}^{H}$. We further assume that $\bar{V}^{H}(W) \leq \bar{V}^{H} \leq V^{H}\left(\overline{\bar{A}}^{\lambda}\right)$, so that $\mathrm{H}$ types are at least as well off as they would be if they revealed their type, and are no better off than they would be under a pooledfair full insurance outcome. This range corresponds with the portion of the efficient frontier in Figure 1. Solving (6) is non-trivial: it involves solving for the $N+1$ year-specific annuity payments for each of the two types. Furthermore, the functions $V^{\sigma}(A)$ are themselves implicitly defined via (4), which is an optimization problem over $N+1$ variables. Nevertheless, (6) is computationally tractable. 
Several factors help us solve (6). First, the assumption that $\bar{V}^{H} \leq V^{H}\left(\overline{\bar{A}}^{\lambda}\right)$ implies that the $\mathrm{L}$ type incentive compatibility constraint will be slack at the solution. We therefore drop this constraint while we are solving (6), and later verify that it is indeed satisfied. Likewise, the budget constraint (BC) trivially binds at the optimum. Second, once the type-L (IC) constraint is dropped, it is easy to see that $A^{H}$ will be a full insurance annuity. Any allocation with an $A^{H}$ that does not offer full insurance can improved upon by replacing $A^{H}$ with the full insurance bundle $\widetilde{A}^{H}$ for which $V^{H}\left(\widetilde{A}^{H}\right)=V^{H}\left(A^{H}\right)$, as this replacement affects (6) (sans $\left(\mathrm{IC}_{\mathrm{L}}\right)$ ) only by making (BC) slack. Since $A^{H}$ is a full insurance annuity, we can parameterize it by $T \equiv W-C^{L}\left(A^{L}\right)$, the size of the cross-subsidy from $\mathrm{L}$ types to $\mathrm{H}$ types expressed in per L type terms. For a given $T, V^{H}\left(A^{H}\right)=\bar{V}^{H}\left(W+\frac{1-\lambda}{\lambda} T\right)$, which means that the solution to (6) must have $T \geq \bar{T}$, where $\bar{T}$ solves $\bar{V}^{H}=\bar{V}^{H}\left(W+\frac{1-\lambda}{\lambda} \bar{T}\right)$. This permits us to write (6) in the simpler form: $\max _{A^{L}, T} V^{L}\left(A^{L}\right)$ subject to

$$
\begin{aligned}
& \left(I C^{\prime}\right) V^{H}\left(A^{L}\right) \leq \bar{V}^{H}\left(W+\frac{1-\lambda}{\lambda} T\right) \\
& \left(M U^{\prime}\right) T \geq \bar{T} \\
& \left(B C^{\prime}\right) C^{L}\left(A^{L}\right) \leq W-T
\end{aligned}
$$

In practice, we solve this program for a given $T$ and then perform a search over different values of $T$ to find the optimum. In discussing (7), we therefore treat $\mathrm{T}$ as given.

Third, we observe that neither type chooses to save at an efficient contract pair. This is obvious for $\mathrm{H}$ types since $A^{H}$ is a full insurance annuity. The $\mathrm{L}$ types have no incentive to save in a constrained efficient market because saving is an inherently inefficient mechanism for transferring income forward in time when there is no bequest motive. It is more efficient to use life-contingent payments so that resources are not "wasted" at death. If an L type receives an annuity $A^{L}$ that induces her to save at some age, then her consumption stream, say $\widetilde{A}^{L}$, would differ from the annuity stream. That same consumption stream could be achieved directly via an annuity at a lower actuarial cost to the annuity 
provider. There is therefore some surplus to be created by reducing the annuity's payouts in its early years and raising its payouts in later years. Insurers in an efficient market will take advantage of such opportunities to repackage the timing of cash flows until the surplus is eliminated and L types no longer wish to save from the annuity. Formally, consider replacing $A^{L}$ with $\widetilde{A}^{L}$ in (7). L types would be exactly as well off as before, but when $A^{L} \neq \widetilde{A}^{L}$ the budget constraint would be made strictly looser. Furthermore, the incentive compatibility constraint will be no tighter, and possibly strictly looser, as a result of the replacement. Therefore, $A^{L}$ can only solve (7) when $A^{L}=\widetilde{A}^{L}$.

The observation that neither type chooses to save means that, in equilibrium, $V^{L}\left(A^{L}\right)=U^{L}\left(A^{L}\right)$ and $V^{H}\left(A^{H}\right)=U^{H}\left(A^{H}\right)$, so both can be computed directly instead of by solving the non-trivial (4). The only part of (7) that is difficult to compute is $V^{H}\left(A^{L}\right)$, the utility that $\mathrm{H}$ types get if they deviate to purchasing the L type annuity and saving optimally. The structure of (7) in fact allows us to evaluate $V^{H}\left(A^{L}\right)$ in solving for equilibrium without explicitly solving (4). In particular, with the parametric forms we assume on the survival probabilities and preferences, $V^{H}\left(A^{L}\right)=\widetilde{V}^{H}\left(A^{L} ; n^{*}\right)$ at any solution to (7) for some $n^{*}$, where

(8) $\widetilde{V}^{H}\left(A_{L} ; n^{*}\right)=\sum_{t=0}^{N} \delta^{t} S_{t}^{H} u\left(\widetilde{c}_{t}^{H}\right)$

and where

$$
\widetilde{c}_{t}^{H}=\left\{\begin{array}{cc}
a_{t}^{L} & \text { if } t<n^{*} \\
\frac{\left(\frac{S_{t}^{H}}{S_{n^{H}}^{H}}\right)^{\frac{1}{y}} \sum_{n=n^{\prime}}^{N} \delta^{n} a_{n}^{L}}{\sum_{n=n^{\prime}}^{N} \delta^{n}\left(\frac{S_{n}^{H}}{S_{n^{*}}^{H}}\right)^{\frac{1}{y}}} & \text { if } t \geq n^{*}
\end{array}\right\}
$$

Equations (8) and (9) describe the utility achieved by an $\mathrm{H}$ type with an annuity stream $A^{L}$ when she consumes the payments before period $n^{*}$, and thereafter follows the consumption pattern she would 
follow if the remaining annuity stream $\left(a_{n^{*}}^{L}, \cdots, a_{N}^{L}\right)$ were a bond against which she could save and borrow at the constant rate $r$. Hence, saying that $V^{H}\left(A^{L}\right)=\widetilde{V}^{H}\left(A^{L} ; n^{*}\right)$ for some $n^{*}$ at a solution to (7) is tantamount to saying that that the optimal consumption pattern of $\mathrm{H}$ types who deviate and buy annuity stream $A^{L}$ is of this form. Note that for their utility to be given by a consumption pattern of this form, the stream $A^{L}$ must be such that this consumption pattern of deviating $\mathrm{H}$ types does not involve borrowing.

The formal proof that annuity stream $A^{L}$ has the property that deviating $\mathrm{H}$ types will optimally consume in accord with (9) is shown in the appendix. The intuition is relatively straightforward, however, and it offers insights into the critical importance of saving in determining the optimum annuity streams. Suppose that annuitants could not save. Then we could find the solution to (7) by simply replacing $V^{H}\left(A^{L}\right)$ with $U^{H}\left(A^{L}\right)$. This modified program could be solved using first order conditions. To illustrate such a solution, Figure 3 plots the annuity streams $A^{L}$ and $A^{H}$ for a special case of the general problem, corresponding to the $\bar{T}=0$ extreme (i.e. the MWS equilibrium) and to the male population in the baseline parameterization of our model, as developed below. The special case also assumes $\gamma=3$ and $r=.03$. Figure 3 shows that $A^{H}$ is a full insurance annuity, and $A^{L}$ is an annuity which is almost a full insurance annuity with significantly higher annuity payments. The payments provided by $A^{L}$ decline with time, but this decline is only significant at late ages - indeed, the decrease is negligible until age 97 . The payments fall off sharply thereafter, but the $A^{L}$ annuity payment only falls below the $A^{H}$ annuity payment at age 100 - the oldest age considered. Between ages 99 and 100, however, the payment falls off so sharply that the incentive compatibility constraint is nevertheless satisfied. Qualitatively similar plots would hold for less extreme values of $\bar{T}$.

The reason the annuity stream $A^{L}$ falls off so steeply and at such an advanced age is because this is when $S^{L} / S^{H}$ is smallest. Low annuity payments translate directly into low consumption when savings is impossible; this hurts $\mathrm{H}$ types much more than $\mathrm{L}$ types at old ages, since $\mathrm{H}$ types are relatively much 
more likely to still be alive. In other words, the best way from the perspective of L types to satisfy incentive compatibility for $\mathrm{H}$ types involves providing a downward tilt at extreme old ages, when the relative probability of $\mathrm{L}$ types being alive, compared to $\mathrm{H}$ types, is lowest.

When savings is possible, such a steep drop-off is far less useful as a self-selection device because it can always be undone - albeit inefficiently - by saving. Indeed, Figure 3 also shows the optimal consumption pattern $\widetilde{c}_{t}^{H}$ and bond-wealth holding of $\mathrm{H}$ types who receive annuity $A^{L}$ but who can also save. These H types optimally choose to consume the annuity payments until age 96 , after which they use their savings to smooth out the sharp drop-off in the annuity stream. Because such saving reduces the power of downward-sloping payout schedules as a selection device, when savings is possible, the extremely sharp fall-off of payments $A^{L}$ will no longer be optimal. However, the incentive for positive saving by deviating $\mathrm{H}$ types will still be as in (9).

\subsection{Optimal Structure of Contracts}

A central contribution of our modeling is finding the optimal structure of annuity contracts when annuitants can save. This involves solving (7). We cannot offer general analytic solutions, so our findings necessarily require assumptions about the underlying functional forms of the utility function, the mortality rates, and other parameters. Using the same baseline parameters that we used in Figure 3, and the same assumption that $\bar{T}=0$, Figure 4 plots the solution to (7) and shows the actuarially fair full insurance annuities for both $\mathrm{H}$ type and L type individuals, as well as the optimal consumption stream of an H type who deviates and purchases annuity $A^{L}$. Again, qualitatively similar graphs would obtain for other values of $\bar{T}$.

Several features of Figure 4 are worthy of note. First, the solution involves substantial crosssubsidies. This is clear from the comparison of the level of the $\mathrm{H}$ type fair level annuity and the $\mathrm{H}$ type optimum annuity $A^{H}$, as $A^{H}$ offers strictly higher payouts. Second, while $A^{L}$ provides a downward sloping annuity stream, it declines much more gradually than the annuity stream shown in Figure 3 , which corresponded to the case in which annuitants could not save. Third, comparison of the optimal 
consumption stream of an $\mathrm{H}$ type deviating to $A^{L}$ reveals that the deviating $\mathrm{H}$ type who purchases $A^{L}$ will immediately begin to save. In the notation above, this means $n^{*}=0$ in (8) and (9).

Comparison of Figures 3 and 4 shows the important effect of allowing for unobservable saving on the structure of the optimal annuity streams. Though it is more difficult to find the optimal annuities with unobservable saving than without, the evident realism that allowing for such saving provides leads us to choose this as our benchmark case. Indeed, the results in Figure 3 suggest that if unobservable saving is not possible, asymmetric information is essentially irrelevant because the optimal annuity streams are virtually identical to the annuity streams that would obtain with symmetric information. The findings more generally suggest caution in using applied contract theoretic models for quantitative purposes when there are inefficient and unobservable behaviors the insured can undertake as a substitute for formal insurance.

\subsection{Discussion of Key Assumptions}

The importance of unobservable savings highlights one of several extensions we have made to the standard stylized model of insurance markets with asymmetric information. These extensions provide a more realistic framework for analyzing the impact of a ban on gender-based pricing. Nonetheless, the model that we develop in (6) and (7), and then solve, makes a number of assumptions for tractability. Some - such as the use of constant relative risk aversion utility or the assumption that individuals discount the future at the rate of interest - are standard. It is worth, however, briefly commenting on several that are more specific to this application.

First, we have not incorporated bequest motives into our model. The importance of bequests in explaining saving behavior has been widely debated, for example by Kotlikoff and Summers (1981), Hurd (1987, 1989), Bernheim (1991), and Brown (2001), but no consensus has emerged. Conceptually, the presence of bequest motives can easily be incorporated into our framework. We would simply add utility from consumption in states when the consumer is dead. Since our solution algorithm relies heavily on the shape of preferences, however, this extension can pose practical issues of computational 
tractability. In part for this reason, we have addressed the analytically more convenient setting without bequests, while recognizing that this limits the applicability of our findings if actual consumption decisions are substantially affected by bequest motives.

Second, we have followed previous theoretical models, notably Hoy (1982) and Crocker and Snow (1986), in modeling mortality heterogeneity via two risk types. The computational challenge of finding optimal contracts is much more difficult in a many-type setting, although similar solution algorithms to the ones we developed here would, in principle, also apply. We show below that our data cannot reject this parsimonious model in favor of one which allows the underlying types to differ by gender.

Finally, we emphasize more generally that while our model incorporates some important features of the U.K. annuity market, it does not capture many others. For example, we focus on single life annuities, and we ignore individuals' option to purchase limited term guarantees of their contracts. We also ignore the presence of wealth outside the retirement accounts. We abstract from the possible presence of risks other than longevity risk, such as liquidity risks or health shocks; Crocker and Snow (2005) discuss how the existence of such "background risks" can affect the insurance market equilibrium. Finally, our model does not allow for the possibility of individuals learning over time about their risk type; Polborn et al. (2004) show that allowing for such dynamic considerations in a model in which individuals have flexibility in the timing of their insurance purchases can have important qualitative effects for the impact of restrictions on characteristic-based pricing. In part because of these and other abstractions, the optimal annuity contracts we compute do not match the actual contracts observed in the data; we discuss this in more detail below.

\section{Model Calibration}

Calibrating our model to yield quantitative estimates of the efficiency and distributional consequences of mandating unisex prices requires the constant relative risk aversion parameter $\gamma$; the real interest rate $r$; the fraction of high risk individuals among men $\left(\lambda^{M}\right)$ and among women $\left(\lambda^{F}\right)$; the fraction $\theta$ of women 
in the relevant population; and the survival curves for each risk type $\left(S^{H}\right.$ and $\left.S^{L}\right)$. We present results for risk aversion coefficients of 1,3 and 5. We assume the interest rate $r$ is equal to 0.03 and set the discount rate $\delta=1 / 1+r$. We set $\theta=0.5$ in our baseline case, but we also report results for other values.

We jointly estimate the remainder of the parameters using micro-data on a sample of compulsory annuitants who bought annuities from a large U.K. life insurance company between 1981 and 1998. We have information on their survival experience through the end of 1998. These data, which are described in more detail in Finkelstein and Poterba (2004), appear to be reasonably representative of the U.K. annuity market. We restrict our attention to annuities that insure a single life, as opposed to joint life annuities that continue to pay out as long as one of several annuitants remains alive. In addition, we focus on individuals who purchased annuities at the modal age for men (age 65). We exclude annuitants who died before their $66^{\text {th }}$ birthday and consider only mortality after age 66 , so that we have a uniform entry age. Our final sample consists of 12,160 annuitants of whom 1,216 are women; this represents about a third of the single-life sample of all ages analyzed in Finkelstein and Poterba (2004).

We estimate the survival curves for two underlying, unobserved risk types $\mathrm{H}$ and L. Our approach, in the spirit of Heckman and Singer (1984), is to assume a parametric form for the baseline mortality hazard, and to jointly estimate the parameters of the baseline and the two multiplicative parameters that capture the unobserved heterogeneity. We follow the actuarial literature on mortality modeling, such as Horiuchi and Coale (1982), and assume a Gompertz functional form for the baseline hazard. This is particularly well suited to our context because our data are sparse in the tails of the survival distribution. Formally, for a given risk type $\sigma$, the mortality hazard at age $x_{i}$ is given by:

$$
\mu\left(x_{i} \mid \sigma\right)=\alpha_{\sigma} \cdot \exp \left(\beta\left(x_{i}-b\right)\right)
$$

where $\mathrm{b}$ is the base age, 65 in our case. We assume that the growth parameter $\beta$ is common to both risk types and to both genders. This means that $\beta$ determines the shape of the mortality curves for both types, 
which differ only in the values of $\alpha_{\sigma}$. Using the notation $t_{i}=x_{i}-b$, this form of the hazard implies risk-type-specific survival function of the form:

$$
S\left(t_{i} \mid \sigma\right)=\exp \left\{\frac{\alpha_{\sigma}}{\beta}\left(1-\exp \left(\beta \cdot t_{i}\right)\right)\right\} .
$$

When the two underlying risk types are the same for males and females, so that only the mix of these two risk types is allowed to differ across genders, our stochastic model depends on a parameter vector $\Theta=$ $\left\{\alpha_{L}, \alpha_{H}, \beta, \lambda_{f}, \lambda_{m}\right\}$. The likelihood function in this case will be:

$$
L(\Theta) \equiv \sum_{i} 1_{m} \cdot\left(\lambda_{m} l_{i}^{H}+\left(1-\lambda_{m}\right) l_{i}^{L}\right)+1_{m} \cdot\left(\lambda_{f} l_{i}^{H}+\left(1-\lambda_{f}\right) l_{i}^{L}\right)
$$

(12) where

$$
l_{i}^{\sigma}=S\left(t_{i} \mid \alpha_{\sigma}, \beta\right)\left(d_{\sigma}+\left(1-d_{i}\right) \mu\left(t_{i} \mid \alpha_{\sigma}, \beta\right)\right), \quad \sigma=\{H, L\}
$$

In (12), the variable $d_{i}$ is an indicator for whether the individual observation is censored and $1_{m}$ and $1_{f}$ are indicator variables for whether an individual is male or female respectively. An individual's contribution to the likelihood function is a weighted average of the likelihood function of a high risk and low risk type, with the weights equal to the gender-specific fraction of high and low risk individuals. Eighty-one percent of the observations in our sample are censored because the annuitant is still alive at the end of the sample period, December 31, 1998.

Table 1 presents our estimates of the mortality model in (11) and (12). Our estimates yield aggregate mortality statistics that are similar to those published by the Institute of Actuaries (1999) for all 65 yearold U.K. pensioners in 1998. For example, the life expectancies implied by our model differ from those in the aggregate tables by only 0.26 years for women and 0.45 years for men. The estimates of the mortality rates for the high risk and the low risk types are quite far apart, implying large differences in life expectancies. For example, the estimates in Table 1 imply that life expectancy at 65 is only 8.8 years for low risk types, compared to 23.2 for high risk types. Column 5 indicates that over 80 percent of women are classified in the high risk (long-lived) group, compared to only about 60 percent of men (column 4). As a result, the estimates imply a 3-year difference in life expectancy at 65 for men compared to women. 
Survival differences this substantial imply the potential for unisex pricing restrictions to accomplish considerable redistribution toward the longer-lived women.

We investigated whether the five-parameter model that we estimate is unnecessarily restrictive by estimating a more flexible eight parameter model that allows for the types to differ across gender. Here, in addition to having a gender specific fraction of high risk types, $\lambda$, the parameters $\alpha_{L}, \alpha_{H}$, and $\beta$ are also permitted to be gender specific. Table 2 shows the results. For men, the estimates of the mortality parameters look qualitatively quite similar to the estimates in Table 1. This is not surprising, since most of the sample is male. The estimates for women indicate a single underling type for women is the best fit for the data. In this case, however, the likelihood function for women varies very little as the model parameters are changed. This explains why we cannot reject the validity of the implicit parameter restrictions involved in using the 5-parameter instead of the 8-parameter model, as indicated by the a likelihood ratio test shown in Table 1 , column $7(\mathrm{p}=.59)$. In light of these results, we use the parameter estimates from our more parsimonious model.

\section{Measuring the Efficiency and Distributional Effects of Banning Gender-Based Pricing}

This section briefly describes the measures that we use to quantify the efficiency and distributional effects of a ban on gender-based pricing in the model described above. Standard measures of the distributional effects of and the efficiency costs of regulatory policies, such as compensating variation, equivalent variation, and their corresponding measures of deadweight burden, do not naturally extend to settings with asymmetric information. It is not clear what it means to estimate the transfer that a consumer of a given type requires to be as well off after a policy intervention as beforehand when it is not possible for the government to identify this consumer and carry out the transfer. With this consideration in mind, we develop a measure of inefficiency that is in the spirit of Debreu $(1951,1954)$. It is also the natural quantification of the efficiency notion used by Crocker and Snow (1986) when they demonstrate that restrictions on categorical pricing in insurance markets are efficiency reducing. 
To construct our efficiency and distribution measures, we use the "actuarial cost function" $C^{\sigma}(A)$ from (5), which gives the expected cost to an insurance company of honoring contract $A$ when it is owned by an individual of risk type $\sigma$. The actuarial cost of honoring a vector $A^{i, \sigma}$ of contracts for each type $i \in\{X, Y\}$ and category $\sigma \in\{H, L\}$ is given by the total actuarial cost function:

$$
\begin{aligned}
T C\left(A^{i, \sigma}\right) & \equiv \theta\left(T C^{Y}\left(A^{Y, \sigma}\right)\right)+(1-\theta)\left(T C^{X}\left(A^{X, \sigma}\right)\right) \\
& \equiv \theta\left(\lambda_{Y} C^{H}\left(A^{Y, H}\right)+\left(1-\lambda_{Y}\right) C^{L}\left(A^{Y, L}\right)\right)+(1-\theta)\left(\lambda_{X} C^{H}\left(A^{X, H}\right)+\left(1-\lambda_{X}\right) C^{L}\left(A^{X, L}\right)\right),
\end{aligned}
$$

where the total cost functions for each category, $T C^{X}$ and $T C^{Y}$, are defined implicitly, and $A^{Y, \sigma}$ and $A^{X, \sigma}$ denote category-specific vectors of contracts. The minimum expenditure function is defined by:

$$
E\left(A^{i, \sigma}\right) \equiv\left\{\begin{array}{cl}
\operatorname{Min}_{\left\{\widetilde{A}^{X, L}, \widetilde{A}^{Y, L}, \widetilde{\widetilde{A}}^{X, H}, \widetilde{A}^{Y, H}\right\}} & \operatorname{TC}\left(\widetilde{A}^{i, \sigma}\right) \\
\text { Subject to } & (I C): V^{\sigma}\left(\widetilde{A}^{i, \sigma}, S^{\sigma}\right) \geq V^{\sigma}\left(\widetilde{A}^{i, \sigma^{\prime}}, S^{\sigma}\right) \forall i \in\{X, Y\} \text { and } \forall \sigma, \sigma \in\{H, L\} \\
\text { and } & (M U): V^{\sigma}\left(\widetilde{A}^{i, \sigma}, S^{\sigma}\right) \geq V^{i}\left(A^{i, \sigma^{\prime}}, S^{\sigma}\right) \forall i \in\{X, Y\} \text { and } \forall \sigma \in\{H, L\}
\end{array}\right.
$$

The minimum expenditure function maps a proposed allocation $A^{i, \sigma}$ of contracts to each type within each category into the minimum total actuarial cost of ensuring that each type within each category is at least as well off as with $A^{i, \sigma}$, while respecting the inherent informational constraints in the economy. These inherent constraints are captured by (IC) in (14), which requires that within each category, individuals need to be willing to choose the contract $\widetilde{A}$ designed for them. Because category is observable, however, incentive compatibility does not have to be satisfied across categories.

An efficient allocation $A^{i, \sigma}$ solves (14). Any other informationally feasible contract set $\widetilde{A}^{i, \sigma}$ that makes each individual as well off as $A^{i, \sigma}$ has at least as high a total actuarial cost. Other allocations are inefficient, and a measure of the inefficiency is $T C\left(A^{i, \sigma}\right)-E\left(A^{i, \sigma}\right)$. If $A_{1}^{i, \sigma}$ and $A_{2}^{i, \sigma}$ denote any two vectors of contracts, the efficiency cost of moving from former to the latter, $E C\left(A_{1}^{i, \sigma}, A_{2}^{i, \sigma}\right)$ is given by (15) $\left.E C\left(A_{1}^{i, \sigma}, A_{2}^{i, \sigma}\right)\right) \equiv\left(T C\left(A_{2}^{i, \sigma}\right)-E\left(A_{2}^{i, \sigma}\right)\right)-\left(T C\left(A_{1}^{i, \sigma}\right)-E\left(A_{1}^{i, \sigma}\right)\right)$ 
For our analysis of the policy of banning the use of categorical pricing, this expression simplifies because, by assumption, the market outcome prior to the ban is efficient. Hence, the efficiency cost of a ban is exactly the inefficiency of the equilibrium contract set that obtains after the ban.

Both $T C(\cdot)$ and $E(\cdot)$ decompose by category, so the efficiency cost of a ban on characteristic-based pricing can be decomposed into category-specific efficiency costs. That is, we can write $T C^{i}\left(A^{i, \sigma}\right)=E^{i}\left(A^{i, \sigma}\right)+$ Inefficiency ${ }^{i}\left(A^{i, \sigma}\right)$. This decomposes the actuarial cost, or the resource use, of a given category into two components: the minimum resources needed to make the types that well off, and the resources that are wasted because of an inefficient allocation. We interpret the former as a money-metric measure of the well being of the category, since the wasted resources do not contribute to well being. We can therefore quantify redistribution at the category level from a policy that changes the contract set from $A_{1}^{i, \sigma}$ to $A_{2}^{i, \sigma}$ as the increase in this money metric measure. Redistribution towards category $\mathrm{Y}$ is therefore given by $R^{Y}\left(A_{1}^{i, \sigma}, A_{2}^{i, \sigma}\right) \equiv\left(E^{Y}\left(A_{2}^{Y, i}\right)-E^{Y}\left(A_{1}^{Y, i}\right)\right)$. There is a similar expression for the redistribution towards category $\mathrm{X}$.

When a policy change has efficiency consequences, the weighted sum across categories of the redistributions will not be zero, even when the policy change leaves the total actuarial cost unchanged. This is because some of the redistribution away from category $\mathrm{X}$ can be dissipated via an increase in the inefficiency of the allocations and might never reach category Y. It is perhaps more appealing to have a redistribution measure in which the entire amount redistributed away from one group is, in fact, redistributed to the other group. We therefore focus on the re-centered measure:

(16) $\widetilde{R}^{Y}\left(A_{1}^{i, \sigma}, A_{2}^{i, \sigma}\right) \equiv R^{Y}\left(A_{1}^{i, \sigma}, A_{2}^{i, \sigma}\right)-\left(\theta R^{Y}\left(A_{1}^{i, \sigma}, A_{2}^{i, \sigma}\right)+(1-\theta) R^{X}\left(A_{1}^{i, \sigma}, A_{2}^{i, \sigma}\right)\right)$. This measure expresses the re-centered redistribution per member of category Y.

Figure 2 can be used to qualitatively illustrate the efficiency and distributional measures when category is perfectly predictive of type (i.e., $\lambda_{X}=0=1-\lambda_{Y}$ ). In this setting, the efficiency metric boils down to summing the certainty equivalent consumptions across types. Prior to the ban, the competitive 
market gives actuarially fair full insurance contracts $A^{L^{*}}$ and $A^{H^{*}}$ to the two types; this allocation, which entails state-independent consumption, is efficient. When categorical pricing is banned, the market implements a pair of contracts labeled $A^{L}$ and $A^{H}$ which is as efficient as it can be, given the government imposed pricing constraints. This set of allocations is nevertheless inefficient because $A^{L}$ could, in principle, be replaced by the state independent (full insurance) consumption contract $A^{\prime L}$ which makes L types equally well off, while saving resources. The efficiency cost of the ban is precisely the difference in the actuarial costs of $A^{L}$ and $A^{\prime L}$, scaled by the number of $L$ types in the market.

The policy also re-distributes resources from L types to $\mathrm{H}$ types. The amount redistributed to each of the $\mathrm{H}$ types, computed without re-centering, is the actuarial difference between $A^{H}$ and $A^{H^{*}}$ computed using mortality risks for $\mathrm{H}$ types. We measure the amount redistributed away from each of the $\mathrm{L}$ types via the actuarial difference between $A^{L^{*}}$ and $A^{\prime L}$, in this case computed using the mortality rates for type L. The change in actual resource use or in the actuarial cost of the L types' contract is measured by the actuarial difference between $A^{L^{*}}$ and $\bar{A}^{L}$, again using L type mortality rates.

When categorization is imperfect, the same sort of analysis applies, but summing certainty equivalents across individuals is no longer a valid measure of efficiency. Because contract outcomes are constrained efficient when categorical pricing is allowed (by assumption), we need only consider the inefficiency of the post-ban equilibrium. Figure 5 illustrates this. The post-ban allocation is given by the contract pair $A^{X, H}=A^{Y, H} \equiv A^{H}$ and $A^{X, L}=A^{Y, L} \equiv A^{L}$. This allocation is inefficient because of the inefficient allocation within the $X$ category. Having fewer $\mathrm{H}$ types within that category means that additional (break even) cross subsidies from $\mathrm{L}$ types to $\mathrm{H}$ types within that category can make both $\mathrm{X}$ category types better off. Hence, both X category types could be made at least as well off with fewer resources, for example via the pair of contracts indicated in Figure 5. On the other hand, because the Y category has a greater fraction of $\mathrm{H}$ types, additional cross subsidies within that category do not yield Pareto improvements - the original contracts are, in fact, the efficient way for $\mathrm{Y}$ category types to achieve 
their original level of well being. The efficiency cost of the ban is measured by the difference in the actuarial costs of the market allocations and the associated efficient allocations.

Because we consider the set of constrained Pareto efficient market outcomes, there is a range of possible market allocations both prior to and subsequent to a ban in gender-based pricing. As a result, there is a range of possible estimates of the consequences of a ban. The efficiency and distributional measures developed above have the nice property that we can summarize all possible efficiency and distributional effects of a ban via a single-parameter family of consequences. This family ranges from a "high efficiency cost, low redistribution" end-member to a "low efficiency cost, high redistribution" endmember. To see this, note that prior to a ban in gender based pricing, the market is, by assumption, efficient. The efficiency cost of a ban is therefore equal to the inefficiency of the post-ban allocation. Moreover, because the market does not implement across gender cross-subsidies in the absence of a ban, the total "welfare" (viz (14)) of each gender prior to the ban is equal to $W$. The distributional consequences can be measured via the "welfare" of each gender in the allocation which obtains when a ban is implemented, regardless of the specifics of the market allocation in the absence of a ban.

The range of possible efficiency and distributional consequences of a ban in gender-based can therefore be computed from the range of possible market outcomes when a ban is in place - i.e., by the solutions to (6) as $\bar{V}^{H}$ varies from the utility $\bar{V}^{H}(W)$ they get from their full insurance actuarially fair contract to the utility $V^{H}\left(\overline{\bar{A}}^{\lambda}\right)$ they get from a pooled (across gender and type) fair full-insurance contract. Furthermore, one can show that the redistribution towards women is monotone increasing in $\bar{V}^{H}$ and that the efficiency cost is strictly decreasing in $\bar{V}^{H}$ until the efficiency cost reaches zero and remains there. Hence, bounding the possible efficiency and distributional consequences of a ban amounts to computing the solution to (6) at the two endpoints, where the lower end of this range corresponds precisely with the MWS equilibrium, and the upper end corresponds with the pooled-fair full-insurance outcome. While this leaves a potentially large range of consequences, it has the advantage of characterizing the full set of feasible constrained-efficient outcomes. Readers who are willing to choose a 
particular equilibrium concept - such as the MWS equilibrium - can narrow the range of possible consequences to a single point.

\section{Estimates of the Efficiency and Distributional Consequences of Banning Gender-Based Pricing}

We begin by reporting findings for our baseline model, in which firms have full flexibility in designing the payment profile of the annuities they offer, individuals can save out of their annuity income, and insurance companies cannot observe saving. After presenting these baseline results, we consider results in several restricted models and then evaluate the sensitivity of our findings to changing several key parameters in our analysis.

\subsection{Baseline Model Results}

To characterize the entire range of possible consequences of a ban in gender based pricing, we need only to compute two possible post-ban allocations: the MWS equilibrium and the pooled-fair full insurance outcome. Without loss of generality, we normalize retirement wealth to $W=1$ for these calculations.

Table 3 summarizes the results associated with both the MWS and the pooled-fair outcome, with the latter labeled SS. The first six columns of Table 3 present the minimum expenditure functions for women, men, and the total population at each of the two extreme contracts which may obtain when categorization is banned. These are $E^{F}, E^{M}$, and $E$, in the notation used above (see (14)). They denote the minimum per person resources needed to ensure that each type is at least as well off as in the equilibrium while respecting the inherent informational constraints of the model. Since each person in endowed with one unit of resources, the difference between the fifth and sixth columns and 1.0 gives the efficiency cost of the ban when the post-ban contracts are given by the MWS and are given by the pooled fair outcomes, respectively. This difference is reported, in percentage terms, in the seventh and eight columns. For a risk aversion coefficient of 1 , the high-end (MWS-end) efficiency cost is 0.04 percent of retirement wealth W. For risk aversion coefficients of 3 and 5, the comparable costs are about 0.02 
percent. If, subsequent to a ban, the market implements the pooled fair endpoint outcome, then there are no associated efficiency costs. It is important to recognize that the small upper bound on the efficiency costs is largely due to our focus on a compulsory annuity market, and that the efficiency costs of eliminating characteristic-based pricing in voluntary insurance markets could be many times greater than our estimates suggest.

The eleventh and twelfth columns of Table 3 report our summary statistics for redistribution from men to women. This is the re-centered redistribution per woman defined in (16). For a risk aversion of 1, we estimate that 2.1 percent of the endowment is redistributed when the market implements the MWS endpoint outcome subsequent to a ban in gender-based pricing. For risk aversion coefficients of 3 and 5 , the comparable numbers are 3.4 percent and 4.1 percent, respectively. The last column of Table 3 reports the efficiency costs as a percentage of the amount of redistribution for the high-end MWS case. This ratio varies from 3.6 percent for a risk aversion of 1 to under 1 percent for a risk aversion of 5 .

When the market implements the pooled-fair outcome instead, it redistributes a total of $7.14 \%$ of resources towards women. This is between 1.8 and 3.4 times more redistribution than the low-end redistribution estimates of Table 3. In addition to providing an endpoint for the possible consequences of a ban in gender-based pricing in our setting, the 7.14 percent redistribution and zero-efficiency cost endpoint is also interpretable as the effect of banning gender-based pricing in a compulsory full-insurance setting such as the U.S. Social Security system. In such a setting individuals are, in effect, required to purchase level inflation-protected annuities with their retirement accumulations $W$. If categorization by gender is allowed and pricing is actuarially fair, men get larger per-period annuity payouts than women for a given initial premium. If categorization is not allowed, all buyers receive the same full insurance annuity with an intermediate payout level. Because there is no scope for insurers to adjust the menu of policies that they offer in response to the ban, such a ban would not have any efficiency costs. The consequences in such a setting are thus identical to the high-distribution endpoint calculations in Table 3.

The smaller redistributive effect of eliminating gender-based pricing in the MWS-endpoints in Table 3, relative to the "Social Security" setting, is a result of the endogenous adjustment of optimal annuity 
profiles, not of reduced demand for annuities by men, since annuitization is mandatory even in our benchmark setting. The reduction in redistribution results from the fact that firms can sell annuity contracts that vary in the time profile of their payout stream and that, by using these profiles for screening purposes, they can partially undo the transfers that take place as a result of the ban on gender-based pricing. This highlights how recognition of the endogenous structure of insurance contracts to government regulation can have important effects on analyses of the regulatory policy.

\subsection{Results in Restricted Models}

We compare the results from our baseline model with those from two alternative models. The first restricts the behavior of annuity buyers by disallowing saving, and the second restricts the behavior of annuity providers by limiting the space of contracts they can offer. These exercises serve two related purposes. First, they help to expand our understanding of how various provisions in our model affect our results. Second, they illustrate the importance of extending the basic model to account for such realworld features as access to savings or limits on the set of contracts insurers can offer. In both cases, we focus exclusively on the high-efficiency cost low-redistribution endpoint, since the other endpoint is unaffected by these changes.

Table 4 summarizes the results of with each of these generalizations. We explained earlier that if annuitants cannot save, or if their saving can be observed and contracted upon by insurance companies, then the MWS equilibrium annuities of short-lived types are characterized by contracts that are level until very old ages, at which point payments fall off quite rapidly. Because long-lived types have a substantial chance of being alive at those old ages, relative to the short-lived types, this shape enforces self-selection at very little cost to the short-lived types. In practice, this means that the MWS equilibrium contracts offered to each sub-population, whether males alone, females alone, or the pooled population, involve zero cross-subsidies from the short-lived to the long-lived types, and the MWS equilibrium coincides with the RSR equilibrium. Bans in categorization have neither efficiency nor distributional consequences in this setting. 
In contrast, restricting the set of contracts that insurers can offer can increase the efficiency costs of a ban on gender-based pricing while reducing the amount of redistribution. This restriction is imposed to more closely accord with the payment profiles of policies actually observed in the U.K. annuity market. While annuity companies appear to use the time-profile of annuity payments to screen individuals according to their risk type in the United Kingdom, Finkelstein and Poterba $(2002,2004)$ report that insurers offer only a limited number of simple alternative payment profiles. Most policies involve level nominal payments; the majority of the remainder involve nominal payments that escalate at a constant rate over time. The declining annuities generated by our baseline model do not have this feature. It is possible that a richer and more realistic model might yield annuities with a structure that more closely accords with observed policies. Another possibility is that there are some implicit restrictions on the form of annuities that can be offered by insurance firms. Such limitations might arise, for example, if there are fixed costs of offering different insurance products, explicit or implicit regulations on legal pension payment profiles, or costs to either the consumer or producer from product complexity.

The particular restriction we consider limits firms to offering only policies which provide benefits that rise or fall at a constant real rate: $a_{t+1}=\eta a_{t}$ for some constant $\eta$ and for all $t$. Subject to this additional requirement, market outcomes are still characterized by (6). As in the unrestricted program, the long-lived types purchase a full-insurance annuity, and short lived types purchase a declining annuity. For the baseline parameters and a risk aversion of 3, the MWS equilibrium rate of decline is 12.1 percent per annum when gender-based pricing is banned, and is 9.5 percent and 13.3 percent for short-lived males and females, respectively, when gender-based pricing is allowed. Table 4 indicates that for a risk aversion of 3, a ban in gender-based pricing in this redistricted contract model redistributes approximately 2.25 percent of retirement wealth towards women, at an efficiency cost of 0.136 percent of retirement wealth. Compared with the results in the baseline model without contract restrictions the maximum amount of redistribution achievable by a ban on gender-based pricing falls by about one-third in a model with contract restrictions; the efficiency costs, while still modest on an absolute scale, rise by an order of 
magnitude. These findings highlight how the nature of the contracting environment and the potential endogenous response to regulation can have substantial effects on the consequences of regulation.

These results also provide insight into why the efficiency costs are so small in the baseline model. There are two mechanisms for satisfying self-selection constraints in an MWS equilibrium. First, the short-lived (L) types can be offered a highly distorted contract, such as a contract with front loading. This distortion makes the L type contract less attractive to both types, but it is a distortion which is differentially more unattractive for the H types. Second, there can be cross-subsidies from the L types' contracts to the H types' contracts. These help satisfy self-selection by making the H type annuity contracts more desirable and the L type annuity contracts less desirable. The efficiency costs will tend to be large when a change in the mix $\lambda$ of $H$ and $L$ types has substantial effects on the optimal amount of distortion in the contract space.

When it is not possible to save, there is essentially no tradeoff between efficiency and redistribution. Distortions can be used to enforce self selection at virtually no costs, so the equilibrium never relies on cross-subsidies. This in turn means that there is no change in the distortion when a ban is put in place, and therefore no efficiency cost. More generally, whenever the marginal costs of distortion are very small for low distortions, and very high at high distortions - with a sharp transition between these two regions the efficiency costs of a ban will tend to be low, as the optimal mix of distortion and cross-subsidization will take place near the transition, irrespective of the relative fraction of low and high-risk types.

Restricting the contract space raises the efficiency cost of a ban on gender-based pricing because the transition is not as sharp in the restricted contracts case. With an unrestricted contract space, it is possible to target an optimal distortion, for example, by making the L type annuity more downward sloping at old ages than at young ages. This flexibility means that the first bit of distortion is the most useful, and additional distortions quickly become less and less useful. In contrast, with the restricted contract spaces we consider, the distortion cannot be targeted: the size of the distortion is fully captured by the downward tilt of the L type annuity. Relative to the unrestricted space, the tradeoff between distortion and crosssubsidy is therefore flatter, making the efficiency cost of banning category-based pricing higher. 


\subsection{Comparative Statics}

To provide some insight into the sensitivity of our results to various parameters, we computed the amount of redistribution and the efficiency cost of banning categorization under three alternative sets of parameter vectors. Table 5 reports the results, again for the high-efficiency low-redistribution endpoint. First, we vary the fraction $\theta$ of women in the population. Our base case in Table 3 assumed a 50-50 gender split. Decreasing $\theta$, to reflect the fact that most participants in the compulsory U.K. annuity market are male, increases the per-woman distributional effects of banning categorization. When there are relatively more men, women gain more by being pooled with the men.

The efficiency cost of a ban, however, is non-monotonic in $\theta$. A change in $\theta$ has two offsetting effects on efficiency. First, the efficiency costs mechanically fall as the relative size of the male population decreases, since the efficiency costs of a ban in categorization in the MWS framework are entirely due to the inefficiency of the post-ban allocation amongst the low risk category, which in this case is men. Second, as the number of women increases, the non-categorizing equilibrium payout moves away from the men's categorizing payout and toward the women's. This raises the efficiency cost per male, and thus creates an effect that operates against the mechanical first effect. Finkelstein and Poterba (2004, 2006) suggest that about 70 percent of U.K. annuitants are male. The results in Table 5 suggest that this raises the amount of redistribution to women and decreases the efficiency cost per dollar of redistribution by about 40 percent compared to our baseline estimates based on the $50-50$ gender split.

The second comparative static we consider involves varying the pair $\alpha_{H}$ and $\alpha_{L}$, the mortality hazard at retirement for the two different risk types. We vary these two in a way that keeps the population average mortality hazard approximately constant at retirement age. The gap between the two risks types in our baseline parameterization may be too large, since, at best, our estimates describe the differences in actual risks across types, as opposed to the private information individuals have when they make annuity purchases. As the hazard rates move closer together, the amount of redistribution that takes place as a result of the ban decreases. The total efficiency cost, however, appears to be robust to the gap 
in the mortality rates. As a result, the efficiency cost per dollar of redistribution rises as the relative hazard declines.

The final variation we consider is jointly varying $\alpha_{H}$ and $\alpha_{L}$ - the age 65 mortality hazards for the two types - and the gender-specific fractions of each risk type, $\lambda_{M}$ and $\lambda_{F}$, in such a way that life expectancies of the two genders remains constant and the aggregate fraction of high risk and low risk types remains unchanged. This is accomplished by first varying $\alpha_{H}$ and $\alpha_{L}$ so as to keep aggregate life expectancy constant, and then by adjusting the gender-specific type fractions to keep the life expectancy of each gender unchanged. Thus, like the previous variation, the thought experiment implicit in this variation is to change the mortality gap; this way of doing so may be more reasonable than the one above. Like the previous variation, this has small but non-zero effects on our estimates of the distributional consequences. With a smaller gap, the distributional consequences are smaller. In contrast with the previous type of mortality gap variation, however, we see that the efficiency consequences can be substantially increased by a lowering of the mortality gap. Indeed, for the smallest gap considered, the efficiency consequences are approximately six times larger than in the baseline case.

\section{Conclusion}

This paper investigates the economic effects of restricting the set of individual characteristics that can be used in pricing insurance contracts. It moves beyond the qualitative observation that such regulations may entail efficiency costs to explore quantitatively both the distributional and efficiency effects of such a policy. To do so, we develop, calibrate, and solve an equilibrium contracting model for the compulsory retirement annuity market in the United Kingdom.

Our findings underscore the importance of considering the endogenous response of insurance contracts to regulatory restrictions when assessing the impact of regulation. Our central estimate suggests that allowing for such endogenous response may reduce estimates of the amount of redistribution from men to women under a ban on gender-based pricing by as much as fifty percent. This estimate contrasts 
the endogenous response case with an alternative in which the menu of policies is fixed, as it is when governments provide compulsory annuities with fixed payout structures in Social Security programs.

The redistribution associated with a unisex pricing requirement, even accounting for the endogenous contract response, remains substantial. Our baseline estimates suggest that at least 3.4 percent of retirement wealth is redistributed from men to women. We also estimate that in the compulsory annuity setting, unisex pricing rules would impose only a modest efficiency cost, approximately 0.02 percent of retirement wealth. Recall, however, that our analysis focuses only on the set of individuals who are already covered by retirement plans that require annuitization of account balances at some point, so nonparticipation in the annuity market is not an option for them. Our efficiency estimates almost certainly understate the efficiency costs of unisex pricing in voluntary annuity markets, since they do not consider consumer decisions about whether or not to participate in the market.

Our estimates also fail to capture the potential long-run behavioral responses to unisex pricing regulations. For example, a change in annuity pricing could affect the savings and labor supply decisions of those who will subsequently face compulsory annuitization requirements. Annuity companies might also respond to unisex pricing requirements by conditioning annuity prices on other observables that are not currently used in pricing policies, such as occupation or location of residence. Discussions of genderneutral pricing in insurance markets also raise interesting questions that range far beyond our study, such as why a society might wish to carry out transfers between men and women, the extent to which genderbased transfers in the marketplace are simply undone within the household, and why insurance markets rather than, say, the tax system, are a natural locus for such transfers. These are all interesting avenues to explore in future work.

Restrictions on the use of gender in pricing retirement annuities are just one of many examples of regulatory constraints on characteristic-based pricing in private insurance markets. Many states in the United States, for example, restrict insurers' use of information on the individual's gender, race, residential location, or past driving history, in setting automobile insurance rates. Similar restrictions apply in homeowner's insurance markets and in many small-group and non-group health insurance 
markets. Moreover, the growing field of medical and genetic testing promises to create new tensions between insurers and regulators, as medical science provides new information that insurers could potentially use to predict the future morbidity and mortality of potential clients for life and health insurance policies.

The framework we have developed provides a natural starting point for evaluating the efficiency and distributional consequences of current or potential future restrictions on characteristic based pricing in these other markets. Such evaluations also raise several new issues which we did not have to confront in the case of unisex pricing requirements for annuities. In the setting we analyze there is scope for choice and self-selection on some of the dimensions of the annuity contract but not on the extensive margin of whether or not to annuitize at all. In addition, while moral hazard is likely to be relatively unimportant in the annuity market, the moral hazard effects of automobile or health insurance may be more pronounced, and will need to be considered in analyzing the efficiency consequences of regulatory restrictions. Finally, gender is an immutable characteristic, unlike geographic location or past driving records, and will therefore not change endogenously in response to the pricing regime. The endogenous adjustment of characteristics to the pricing regime is another interesting issue that future work should consider. 


\section{REFERENCES}

Bernheim, B. Douglas (1991). "How Strong are Bequest Motives? Evidence Based on Estimates of the Demand for Life Insurance and Annuities." Journal of Political Economy 99, 899-927.

Blackmon, B. Glenn, Jr., and Richard J. Zeckhauser (1991). "Mispriced Equity: Regulated Rates for Auto Insurance in Massachusetts," American Economic Review 81, 65-69.

Boadway, Robin, and Peter Townley (1988), "Social Security and the Failure of Annuity Markets." Journal of Public Economics 35, 75-96.

Brown, Jeffrey R. (2001). "Private Pensions, Mortality Risk, and the Decision to Annuitize." Journal of Public Economics 82, 29-62.

Brunner, Johann K. and Susanne Pech (2005). "Adverse Selection in the Annuity Market when Payoffs Vary over the Time of Retirement." Journal of Institutional and Theoretical Economics 161, 155-183.

Buchmueller, Thomas and John DiNardo (2002). "Did Community Rating Induce an Adverse Selection Death Spiral? Evidence from New York, Pennsylvania and Connecticut.” American Economic Review 92, 280-294.

Crocker, Keith J. and Arthur Snow (1985). "The Efficiency of Competitive Equilibria in Insurance Markets with Asymmetric Information.” Journal of Public Economics 26, 207-219.

Crocker, Keith J. and Arthur Snow (1986), "The Efficiency Effects of Categorical Discrimination in the Insurance Industry," Journal of Political Economy 94, 321-344.

Crocker, Keith and Arthur Snow. 2005. "Screening in Insurance Markets with Adverse Selection and Background Risk." Mimeo.

Debreu, Gerard. (1951). "The Coefficient of Resource Allocation.” Econometrica 19 (3), 273-292.

Debreu, Gerard. (1954). “A Classical Tax-Subsidy Problem.” Econometrica 22, 14-22.

Eichenbaum, Martin S. and Dan Peled (1987). "Capital Accumulation and Annuities in an Adverse Selection Economy." Journal of Political Economy, 95, 334-54.

Finkelstein, Amy and James Poterba (2002). "Selection Effects in the Market for Individual Annuities: New Evidence from the United Kingdom," Economic Journal 112, 28-50.

Finkelstein, Amy and James Poterba (2004). "Adverse Selection in Insurance Markets: Policyholder Evidence from the U.K. Annuity Market," Journal of Political Economy 112, 183-208.

Finkelstein, Amy and James Poterba. (2006). "Testing for Adverse Selection with Unused Observables" Unpublished mimeo.

Heckman, James and Burton Singer (1984). "Econometric Duration Analysis," Journal of Econometrics 24, 63-132.

Hirshleifer, Jack (1971). "The Private and Social Value of Information and the Reward to Inventive Activity," American Economic Review 61, 561-574.

Horiuchi, Shiro and Ansley Coale (1982). "A Simple Equation for Estimating the Expectation of Life at Old Ages," Population Studies 36, 317-326.

Hoy, Michael (1982). "Categorizing Risks in the Insurance Industry," Quarterly Journal of Economics 96, 321-336.

Hurd, Michael (1987). "Savings of the Elderly and Desired Bequests." American Economic Review 77, 298-312.

Hurd, Michael (1989). "Mortality Risk and Bequests.” Econometrica 57, 779-814.

Institute of Actuaries. 1999. Continuous Mortality Investigation Reports Numbers 16 and 17.

Kotlikoff, Laurence and Lawrence Summers (1981). "The Role of Intergenerational Transfers in Aggregate Capital Formation" The Journal of Political Economy 89, 706-732.

Miyazaki, Hajime (1977), "The Rate Race and Internal Labor Markets," Bell Journal of Economics 8, 394-418. 
Polborn, Mattias, Michael Hoy, and Asha Sadanand (2006). “Advantageous Effects of Regulatory Adverse Selection in the Life Insurance Market." Economic Journal 116, 327-354.

Posner, Richard (1971), “Taxation by Regulation," Bell Journal of Economics 2 (1), 22-50.

Rothschild, Michael and Joseph E. Stiglitz (1976), "Equilibrium in Competitive Insurance Markets: An Essay on the Economics of Imperfect Information," Quarterly Journal of Economics 90, 630-649.

Simon, Kosali. (Forthcoming). "Adverse Selection in Health Insurance Markets: Evidence from State Small-group health insurance reforms." Journal of Public Economics

Spence, Michael (1978), "Product Differentiation and Performance in Insurance Markets," Journal of Public Economics 10 (3), 427-447

Wilson, Charles (1977). “A Model of Insurance Markets with Incomplete Information,” Journal of Economic Theory 16, 167-207. 


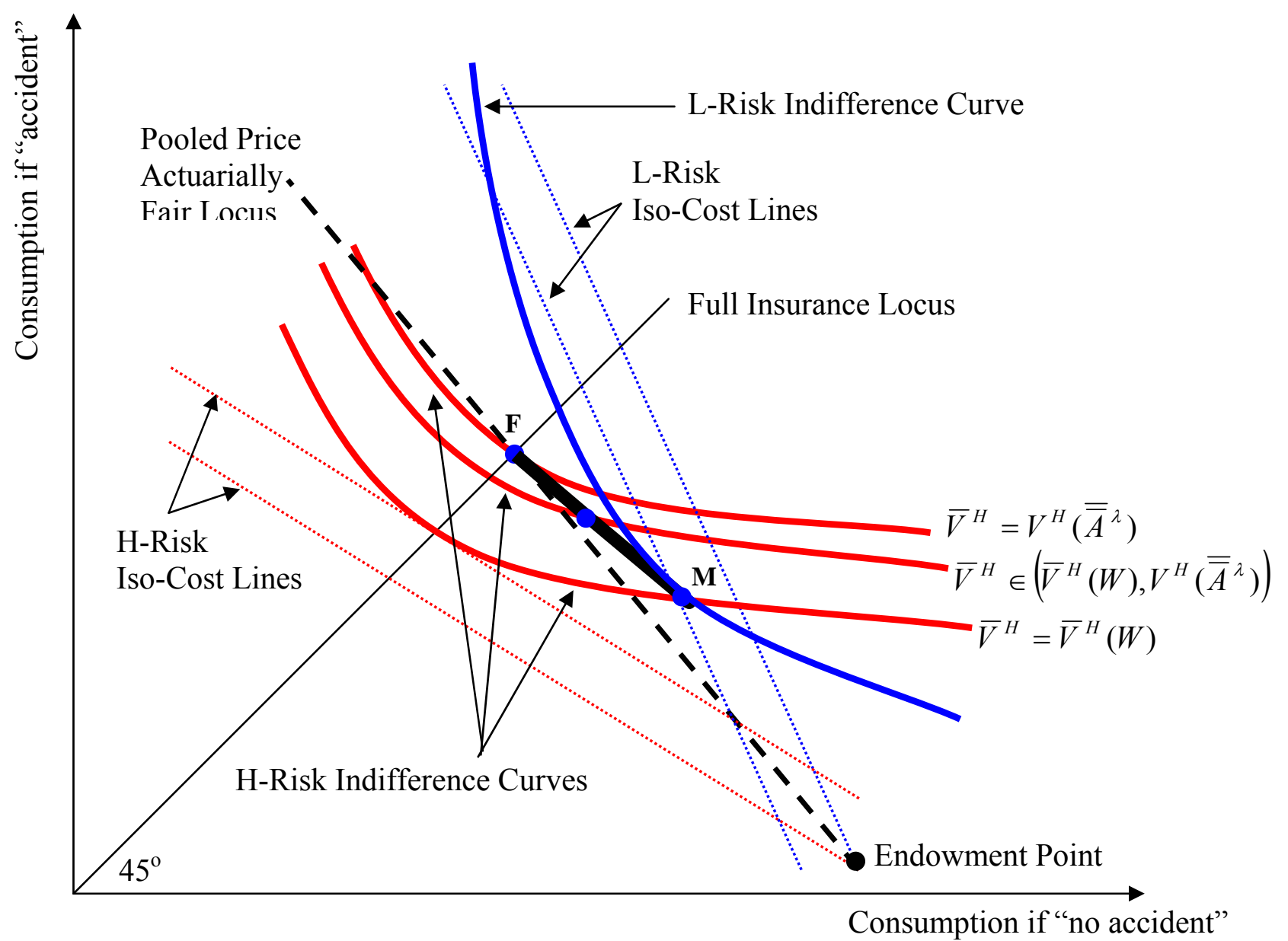

Figure 1: Stylized constrained Pareto frontier.

The dark curve connecting M to F depicts a portion of the locus of the L-type consumption points at constrained Pareto optimal outcomes. Specifically, it depicts the L-type consumptions consistent with:

(i) H-types receiving full insurance consumption;

(ii) The H-types incentive compatibility constraint binding;

(iii) Firms breaking even on aggregate, and

(iv) $\mathrm{H}$-types being no better off than at $\mathrm{F}$.

A symmetric portion of this frontier (corresponding with even larger cross-subsidies from L- to H-types) lies on the other side of the full insurance locus. 


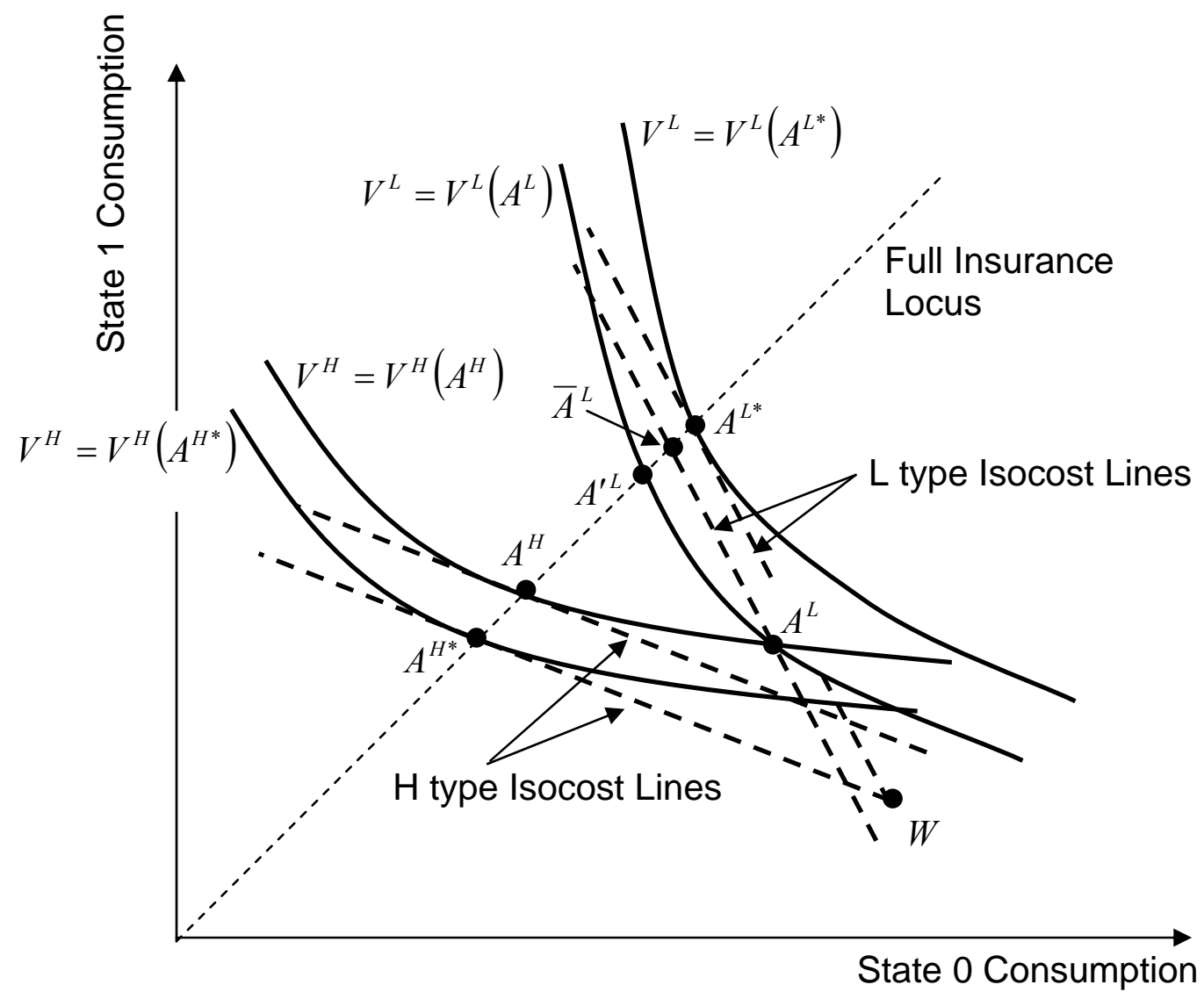

Figure 2: A Constrained Efficient Annuity Pair 


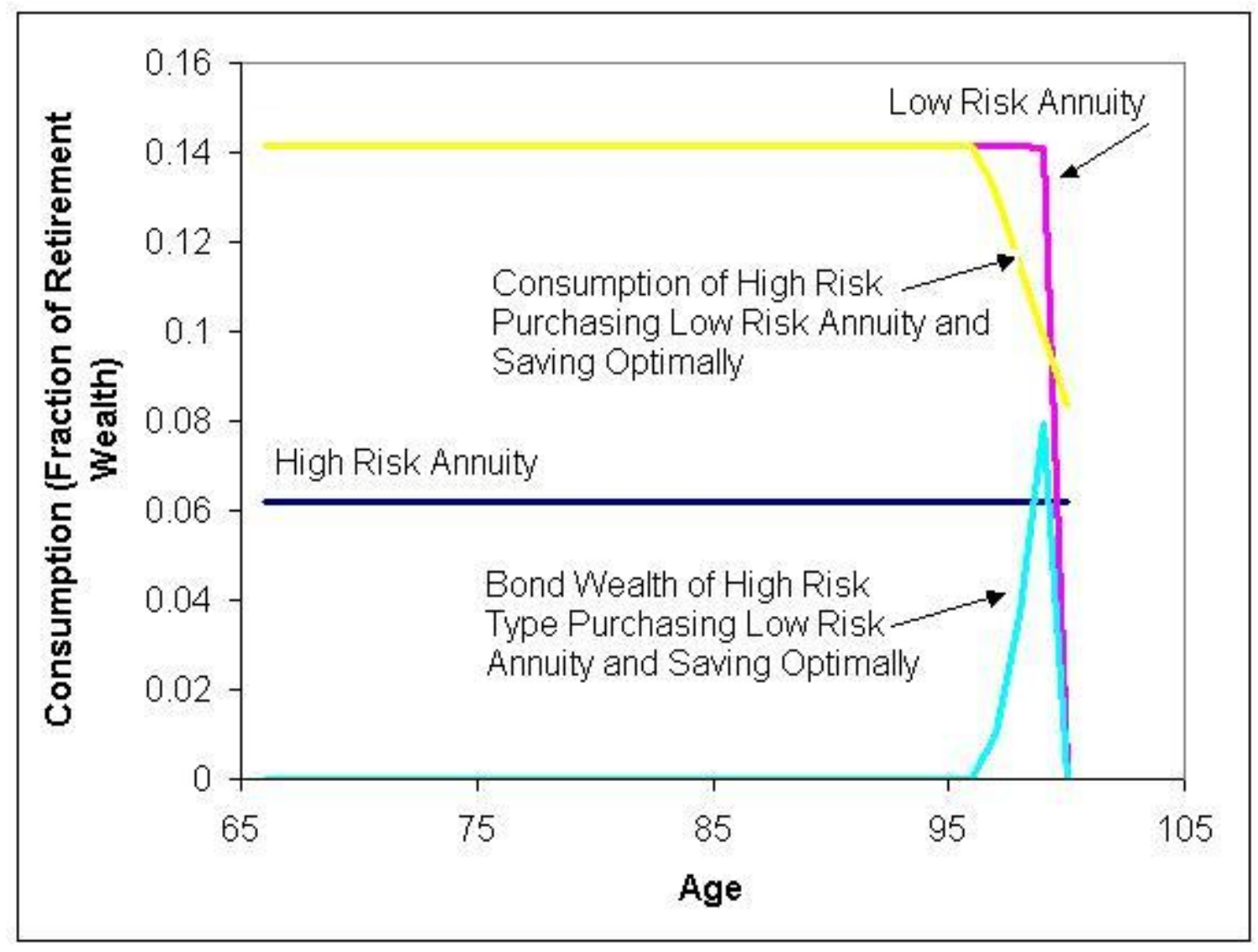

Figure 3: MWS Equilibrium Annuities if Savings is Impossible (Male population, $\gamma=3$ ) 


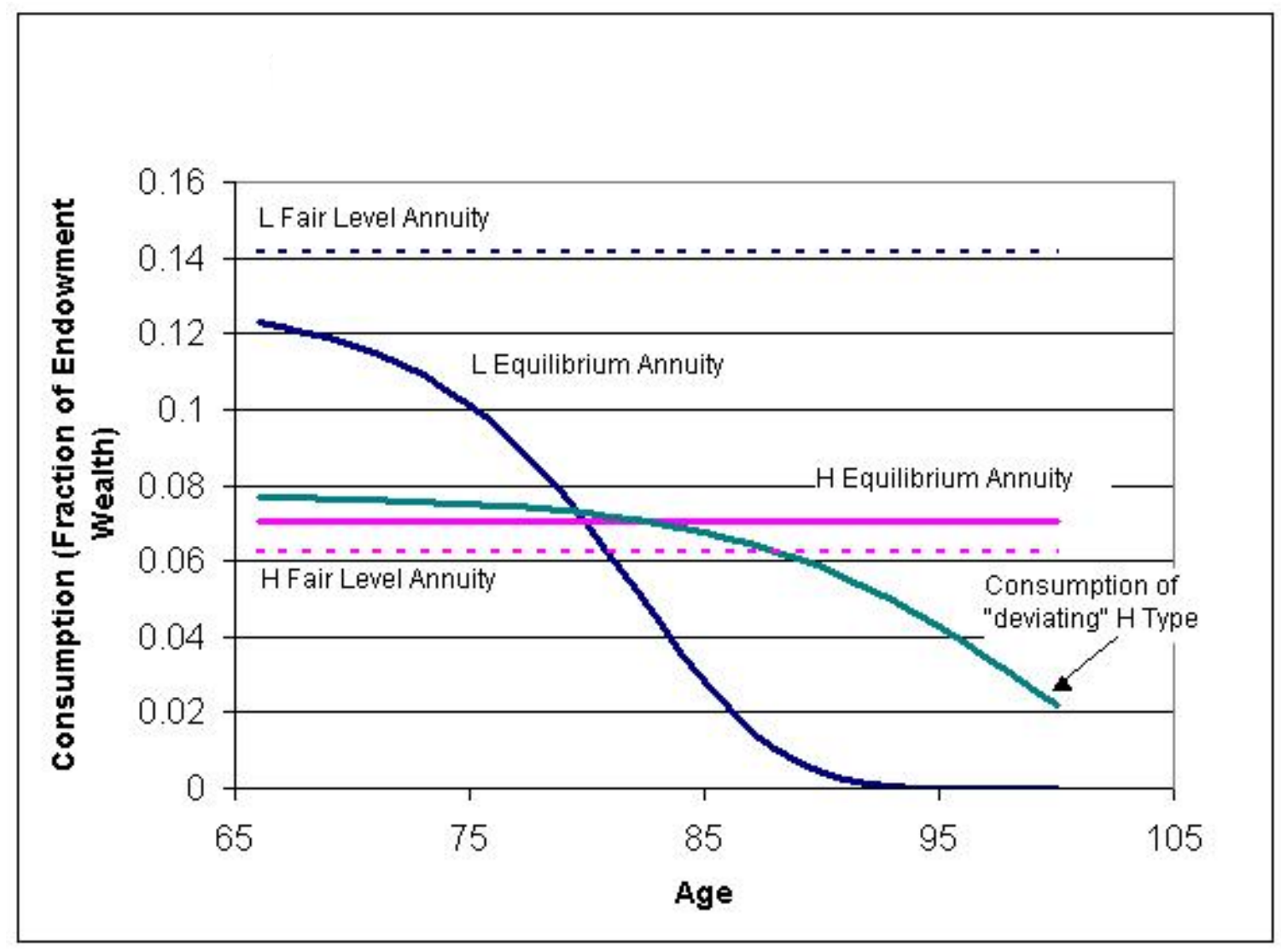

Figure 4: MWS Equilibrium Annuities if Unobservable Savings is Possible (Male population, $\gamma=3$ ) 


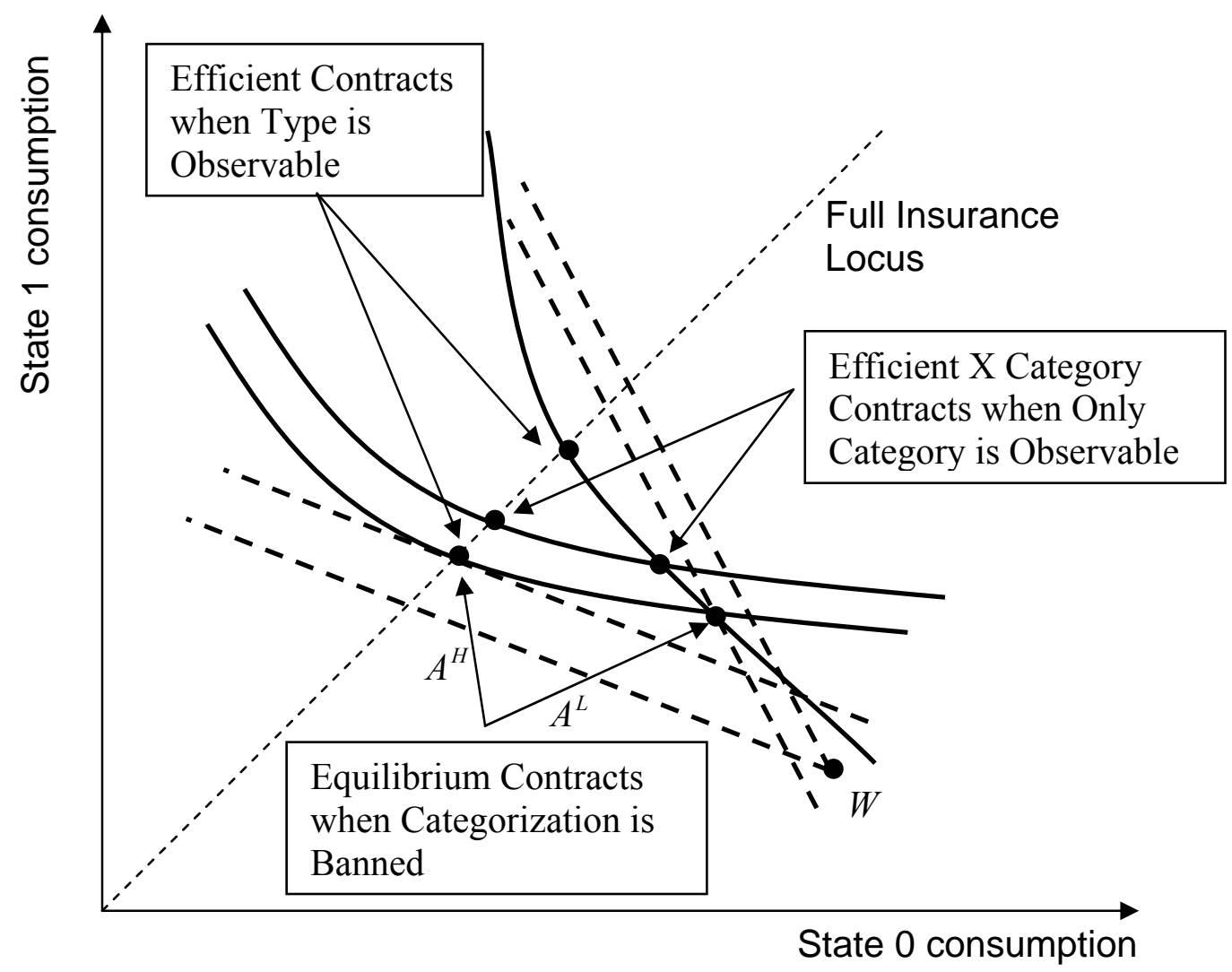

Figure 5: The inefficiency of bans in categorical pricing 
Table 1: Estimates of Two-Type Gompertz Mortality Hazard Model, Same Types for Both Genders

\begin{tabular}{|c|c|c|c|c|c|c|c|}
\hline Sample & $\begin{array}{l}\text { Multi- } \\
\text { plicative } \\
\text { factor on } \\
\text { hazard } \\
\text { for high } \\
\text { risk }\left(\alpha_{H}\right)\end{array}$ & $\begin{array}{l}\text { Multi- } \\
\text { plicative } \\
\text { factor on } \\
\text { hazard for } \\
\text { low risk } \\
\left(\alpha_{L}\right)\end{array}$ & $\begin{array}{l}\text { Common } \\
\text { growth } \\
\text { factor in } \\
\text { hazard } \\
\text { model } \\
(\beta)\end{array}$ & $\begin{array}{l}\text { Fraction of } \\
\text { men who } \\
\text { are high } \\
\text { risk }\left(\lambda_{M}\right)\end{array}$ & $\begin{array}{l}\text { Fraction of } \\
\text { women } \\
\text { who are } \\
\text { high risk } \\
\left(\lambda_{F}\right)\end{array}$ & $\log (\mathrm{L})$ & $\begin{array}{l}\chi^{2}(3) \\
(P- \\
\text { value })\end{array}$ \\
\hline $\begin{array}{l}65 \text { Year Olds } \\
(\mathrm{N}=12160)\end{array}$ & $\begin{array}{l}0.0031 \\
(0.0003)\end{array}$ & $\begin{array}{l}0.0405 \\
(0.0013)\end{array}$ & $\begin{array}{l}0.1485 \\
(0.0056)\end{array}$ & $\begin{array}{l}0.6051 \\
(0.0096)\end{array}$ & $\begin{array}{l}0.8192 \\
(0.0231)\end{array}$ & -10347.45 & $\begin{array}{l}1.94 \\
(0.59)\end{array}$ \\
\hline
\end{tabular}

Notes: Results are based on estimating equation (12) using micro-data on annuitant mortality patterns. Standard errors are in parentheses. Column 6 contains the total $\log$ likelihood. Column 7 reports the $\chi^{2}(3)$ statistic $(P$-value) for the Likelihood Ratio test of this restriction relative to the more flexible specification in Table 2.

Table 2: Estimates of Two-Type Gender-Specific Gompertz Mortality Model

\begin{tabular}{lllllll}
\hline Sample & $\begin{array}{l}\text { Multiplicative } \\
\text { factor on } \\
\text { hazard for high } \\
\text { risk }\left(\alpha_{H, m} / \alpha_{H, f}\right)\end{array}$ & $\begin{array}{l}\text { Multiplicative } \\
\text { factor on hazard } \\
\text { for low risk } \\
\left(\alpha_{L, m} / \alpha_{L, f}\right)\end{array}$ & $\begin{array}{l}\text { Common } \\
\text { growth factor } \\
\text { in hazard } \\
\text { model }\left(\beta_{m} / \beta_{f}\right)\end{array}$ & $\begin{array}{l}\text { Fraction } \\
\text { who are } \\
\text { high risk } \\
\left(\lambda_{m} / \lambda_{f}\right)\end{array}$ & $\begin{array}{l}\log (\mathrm{L}), \\
\text { by gender }\end{array}$ & $\log (\mathrm{L})$ \\
\hline $\begin{array}{l}\text { 65 Year Old } \\
\text { Males }(m)\end{array}$ & $\begin{array}{l}0.0030 \\
(0.0003)\end{array}$ & $\begin{array}{l}0.0423 \\
(0.0014)\end{array}$ & $\begin{array}{l}0.1566 \\
(0.0058)\end{array}$ & $\begin{array}{l}0.6305 \\
(0.0091)\end{array}$ & -9568.59 & \\
$\begin{array}{l}\text { 65 Year Old } \\
\text { Females }(f) \\
(\mathrm{N}=1216)\end{array}$ & 0.0111 & $\mathrm{NA}$ & 0.0882 & NA & -777.89 & -1036.4 \\
\hline
\end{tabular}

Notes: Results are based on estimating equation (12) separately for each gender using the same data as in Table 1 Standard errors are in parentheses. The estimation for females led to a single type model. The final column reports the total log likelihood.

Table 3: Range of Efficiency and Distributional Consequences of Unisex Pricing

\begin{tabular}{|c|c|c|c|c|c|c|c|c|c|c|c|}
\hline \multirow{3}{*}{$\begin{array}{l}\text { Coef' } \\
\text { of } \\
\text { Rel've } \\
\text { Risk } \\
\text { Aver- } \\
\text { sion }\end{array}$} & \multicolumn{8}{|c|}{$\begin{array}{l}\text { Required Per-Person Endowment Needed to Achieve Utility Level from } \\
\text { Non-Categorizing Equilibrium When Categorization is Allowed }\end{array}$} & \multirow{2}{*}{\multicolumn{2}{|c|}{$\begin{array}{l}\text { Redistribution to } \\
\text { Women }\left(\widetilde{R}^{W}\right) \text {, } \\
\text { Per Woman, as a } \\
\% \text { of Endowment }\end{array}$}} & \multirow{3}{*}{$\begin{array}{l}\text { Eff'cy } \\
\text { Cost } \\
\text { Per } \\
\text { Dollar } \\
\text { Redistn } \\
\text { MWS }\end{array}$} \\
\hline & \multicolumn{2}{|c|}{ Women $\left(E^{W}\right)$} & \multicolumn{2}{|c|}{$\operatorname{Men}\left(E^{M}\right)$} & \multicolumn{2}{|c|}{$\begin{array}{l}\text { Total } \\
\text { Pop'n }(E)\end{array}$} & \multicolumn{2}{|c|}{$\begin{array}{l}\text { Eff'cy Cost as } \\
\% \text { of Total } \\
\text { Endowment }\end{array}$} & & & \\
\hline & MWS & SS & MWS & SS & MWS & SS & MWS & $\mathrm{SS}$ & MWS & SS & \\
\hline$\gamma=1$ & $0<05$ & 1.0714 & & & & & & 0 & & & $3.66 \%$ \\
\hline$y=3$ & 1.0336 & 1.0714 & $0 . \subseteq$ & 0.9286 & 98 & 1 & 0.0246 & 0 & 3.387 & 7.14 & 1.45 \\
\hline$\gamma=5$ & 1.0404 & 1.0714 & 0.9593 & 0.9286 & 0.9998 & 1 & 0.0180 & 0 & 4.055 & 7.14 & 0.89 \\
\hline
\end{tabular}

Notes: Estimates are based on the model and algorithm described in the text. Columns labeled MWS refer to the high efficiency cost/low redistribution end of the range of possible consequences which obtains when the market implements the Miyazaki-Wilson-Spence equilibrium when gender-based pricing is banned. Columns labeled SS refer to the zero efficiency cost/high redistribution end of the range which obtains when the market implements a pooled-fair full insurance "Social Security-like" outcome when gender based pricing is banned. The MWS contracts are computed using Equation (6) and the risk type-distributions estimated in Table 1, pooled across genders. Columns (1)-(6) are computed using Equation (15) and columns (9)-(10) are computed using Equation (16). 
Table 4: Efficiency and Distributional Effects of Ban on Gender Based Pricing in Restricted Models

\begin{tabular}{|c|c|c|c|c|}
\hline & \multicolumn{2}{|c|}{$\begin{array}{l}\text { Redistribution to Women }\left(\widetilde{R}^{W}\right), \text { Per } \\
\text { Woman (as \% of Endowment) }\end{array}$} & \multicolumn{2}{|c|}{$\begin{array}{l}\text { Efficiency Cost as \% of } \\
\text { Endowment }\end{array}$} \\
\hline & MWS & SS & MWS & SS \\
\hline & \multicolumn{4}{|c|}{$\gamma=1$} \\
\hline Unrestricted (Baseline) Model & 2.0838 & 7.14 & 0.0381 & 0 \\
\hline No Savings Model & 0 & 7.14 & 0 & 0 \\
\hline Restricted Contracts Model & 1.3326 & 7.14 & 0.1000 & 0 \\
\hline & \multicolumn{4}{|c|}{$y=3$} \\
\hline Unrestricted (Baseline) Model & 3.3874 & 7.14 & 0.0246 & 0 \\
\hline No Savings Model & 0 & 7.14 & 0 & 0 \\
\hline Restricted Contracts Model & 2.2504 & 7.14 & 0.1358 & 0 \\
\hline & \multicolumn{4}{|c|}{$y=5$} \\
\hline Unrestricted (Baseline) Model & 4.0549 & 7.14 & 0.0180 & 0 \\
\hline No Savings Model & 0 & 7.14 & 0 & 0 \\
\hline Restricted Contracts Model & 2.8690 & 7.14 & 0.1352 & 0 \\
\hline
\end{tabular}

Notes: Unrestricted (Baseline) Model calculations are as in Table 3. The Restricted Contracts Model calculations are described in Section 5.2: in this model, firms can only offer contracts with constant escalation or declination rates. In the No Savings Model, individuals are assumed to have no access to savings technology, as described in Section 5.2. 
Table 5: Sensitivity Analysis for Redistribution and Efficiency Cost Calculations, $(\gamma=3)$

\begin{tabular}{|c|c|c|c|c|c|c|}
\hline \multirow[t]{2}{*}{$\begin{array}{l}\text { Parameter Being Varied and } \\
\text { New Value }\end{array}$} & \multicolumn{2}{|c|}{$\begin{array}{l}\text { Redistribution to } \\
\text { Women }\left(\widetilde{R}^{W}\right) \text {, Per } \\
\text { Woman (as \% of } \\
\text { Endowment) }\end{array}$} & \multicolumn{2}{|c|}{$\begin{array}{l}\text { Efficiency Cost as \% of } \\
\text { Endowment }\end{array}$} & \multicolumn{2}{|c|}{$\begin{array}{l}\text { Efficiency Cost Per Dollar } \\
\text { of Distribution }\end{array}$} \\
\hline & MWS & SS & MWS & SS & MWS & SS \\
\hline \multicolumn{7}{|l|}{$\theta$ (fraction women) } \\
\hline 0.1 & $6.37 \%$ & $13.63 \%$ & $0.00 \%$ & $0 \%$ & $0.32 \%$ & $0 \%$ \\
\hline 0.3 & 4.84 & 10.30 & 0.01 & 0 & 0.89 & 0 \\
\hline 0.5 & 3.39 & 7.14 & 0.02 & 0 & 1.45 & 0 \\
\hline 0.7 & 2.00 & 4.17 & 0.03 & 0 & 1.97 & 0 \\
\hline 0.9 & 0.66 & 1.35 & 0.01 & 0 & 2.40 & 0 \\
\hline \multicolumn{7}{|c|}{$\alpha_{H}, \alpha_{L}=$ Mortality hazard at age 65 for low-risk and high-risk type } \\
\hline $.001, .046$ & $4.72 \%$ & $8.63 \%$ & $0.02 \%$ & $0 \%$ & $0.91 \%$ & $0 \%$ \\
\hline $.002, .043$ & 3.98 & 7.85 & 0.02 & 0 & 1.18 & 0 \\
\hline $.0031, .041$ & 3.39 & 7.14 & 0.02 & 0 & 1.45 & 0 \\
\hline $.005, .036$ & 2.62 & 6.01 & 0.03 & 0 & 1.97 & 0 \\
\hline $.008, .028$ & 1.65 & 4.16 & 0.03 & 0 & 3.27 & 0 \\
\hline \multicolumn{7}{|c|}{$\left(\alpha_{H}, \alpha_{L}\right),\left(\lambda_{m}, \lambda_{f}\right):$ Age 65 mortality hazards and type fractions } \\
\hline$(0.0021,0.2492),(0.6445,0.7798)$ & $4.69 \%$ & $7.89 \%$ & $0.01 \%$ & $0 \%$ & $0.38 \%$ & $0 \%$ \\
\hline$(0.0026,0.0793),(0.6275,0.7968)$ & 3.82 & 7.45 & 0.02 & 0 & 0.82 & 0 \\
\hline$(0.0031,0.0405),(0.6051,0.8192)$ & 3.39 & 7.14 & 0.02 & 0 & 1.45 & 0 \\
\hline$(0.0036,0.0248),(0.5738,0.8505)$ & 3.09 & 6.92 & 0.04 & 0 & 2.58 & 0 \\
\hline$(0.0041,0.0169),(0.5268,0.8976)$ & 2.86 & 6.78 & 0.07 & 0 & 4.90 & 0 \\
\hline$(0.0046,0.0122),(0.4477,0.9770)$ & 2.64 & 6.62 & 0.14 & 0 & 10.72 & 0 \\
\hline
\end{tabular}

Note: Same calculations as in Table 3 with varying parameters. Results for baseline parameters from Table 3 appear in bold. The mortality hazards for high and low risk types at age 65 are varied while keeping the aggregate mortality rate at age 65 constant. The mortality hazards and type fractions in the bottom panel are varied to keep aggregate type fractions and gender-specific life expectancies constant. 


\section{Appendix: Solution Algorithm for Program (7)}

This appendix describes and proves the validity of our procedure for solving Program (7) in the text. The difficult part of solving (7) stems from the need to compute $V^{H}\left(A^{L}\right)$, the utility $H$ types achieve when they purchase the annuity contract designed for the $L$ types and save optimally. We deal with this difficulty by identifying the structure of the optimal saving pattern of deviating $H$ types at the solution to (7).

There are two key features to this structure. First, deviating $H$ types have an incentive to save only at old ages. There is some period $n^{*}$ before which deviating $H$ types consume the annuity stream. We can therefore solve for $V^{H}\left(A^{L}\right)$ by examining the savings behavior in periods $n \geq n^{*}$ only. Second, deviating $H$ types will optimally carry strictly positive wealth forward at every date $n \geq n^{*}$. Intuitively, absent savings the $\left(I C^{\prime}\right)$ constraint in (7) could be satisfied with an annuity stream $A^{L}$ which drops off very steeply at very old ages. Such an annuity would provide $H$ types with an incentive to save at old ages, undermining the effectiveness and desirability of the steep drop off. The ability of $H$ types to save therefore pushes the "drop off" in the annuity $A^{L}$ to earlier dates than would otherwise be optimal. For this reason, deviating $H$ types never have incentive to borrow at the optimal $A^{L}$ : if they did, $A^{L}$ could be improved by pushing the "drop off" back towards later ages.

The first feature is important for us: at the heart of our solution procedure is an algorithm to find the $n^{*}$ after which the deviating $H$ type's begin to do something other than just consume the annuity stream. The second feature is important because it makes (7) analytically tractable. To see why, contrast the indirect utility of deviating $H$ types in two situations. In both, take their behavior before $n$ to involve the direct consumption of the annuity stream $A^{L}$ prior to $n$. The two situations only differ in the potential behavior after $n$.

In the first situation, we know nothing about the post- $n$ savings behavior of $H$ types, so we must solve:

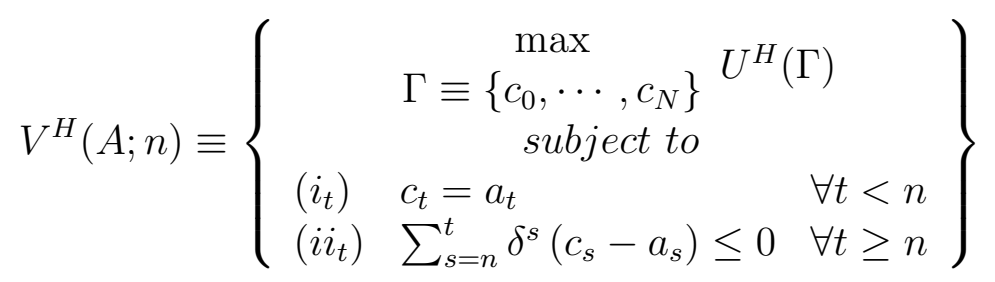


to find their utility from a given consumption stream. In the second situation, we know that $H$ types will always choose to carry positive wealth after $n$. This means that we can instead solve:

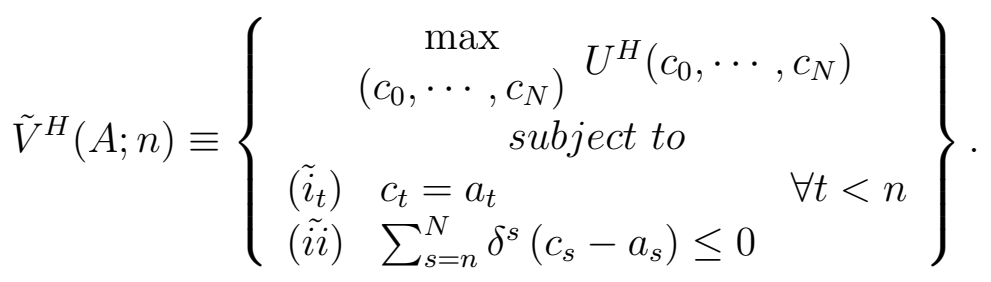

Programs (17) and (18) differ in the constraints $\left(i i_{t}\right)$ and $(\tilde{i i})$. The former involves one "no borrowing" constraint for each period $t \geq n$ : the total resources consumed through period $t$ cannot exceed the total resources received up to that point. In contrast, the latter only has a single "lifetime" resource constraint. When we know that $H$ types will always choose to carry positive wealth after $n$, we know that the no borrowing constraints are slack, and we can drop all of them except the whole-life no borrowing constraint.

Program (18) is easily solved using first order methods. With constant relative risk aversion utility, this solution yields a closed-form expression for $\tilde{V}^{H}(A ; n)$ and its derivatives. This allows us to solve (7) using first order methods once we have identified the cutoff value $n^{*}$. We will present our algorithm for constructing $n^{*}$ below.

Before presenting our algorithm, let us formalize the preceding intuition. Suppose we knew that deviating $H$ types would consume the entire annuity payment in each period prior to $n$. Fix a Lagrange multiplier $\nu$ on constraint $\left(I C^{\prime}\right)$ in (7), fix a $\bar{T}$ for which constraint $\left(M U^{\prime}\right)$ binds, let $\bar{V}=\bar{V}^{H}(W+$ $\left.\frac{1-\lambda}{\lambda} \bar{T}\right)$, and let $\bar{W}=W-\bar{T}$. Then solving (7) for this fixed $\nu$ and $\bar{T}$ would be equivalent to solving the program

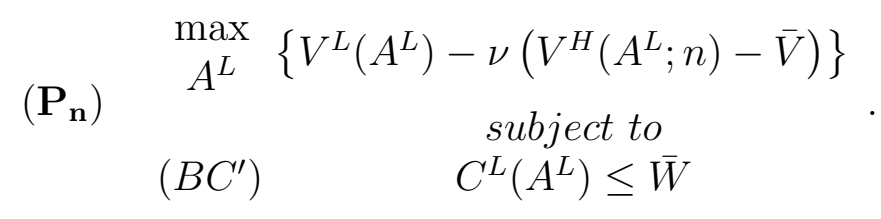

Solving $(7)$ is always equivalent to solving $\left(P_{0}\right)$ for the proper value of $\nu$ and $\bar{T}$. When we know that deviating $H$ types will consume the entire annuity payment in each period prior to $n$, solving $\left(P_{n}\right)$ is equivalent to solving $\left(P_{0}\right)$ as well. If we additionally knew that $H$ types would carry strictly positive wealth in every period after $n$, solving $\left(P_{n}\right)$ would also be equivalent to solving 
the program:

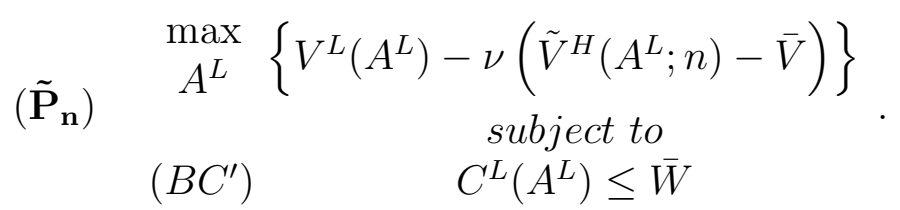

When we know the two features of deviating $H$ type's consumption patterns are satisfied and we know the cutoff $n^{*}$, solving $\left(\tilde{P}_{n^{*}}\right)$ will therefore also solve (7). This is important, because the closed, tractable form of $\tilde{V}^{H}(A ; n)$ allows us to solve $\left(\tilde{P}_{n}\right)$ using first order methods.

We will now present Algorithm 1, which we use to construct $n^{*}$. The remainder of the appendix will be devoted to showing that the solutions to $\left(P_{0}\right)$ and $\left(\tilde{P}_{n^{*}}\right)$ coincide for this $n^{*}$. This is formally stated in Proposition 1 below, but we will need to establish several lemmas before we can prove it. Once we have proved it, we will know that applying Algorithm 1 to find $n^{*}$ and then solving $\left(\tilde{P}_{n^{*}}\right)$ will solve $(7)$ for the given $\nu$, and we will be done.

First we define a parameter $n_{\max }^{*}$ which will play an important role in Algorithm 1. To motivate it, imagine solving $\left(P_{N}\right)$ for $A^{L *}=\left(a_{0}^{L *}, \cdots, a_{N}^{L *}\right)$. If it happens that

$$
S_{n}^{H}\left(a_{n}^{L *}\right)^{-\gamma} \geq S_{n+1}^{H}\left(a_{n+1}^{L *}\right)^{-\gamma} \text { for } n=0 \cdots, N-1,
$$

then $H$ types will have no incentive to save when given annuity $A^{L *}$. Hence, $A^{L *}$ will also solve the tighter program $\left(P_{0}\right)$. To see when $(19)$ is possible, consider the first order conditions for $a_{n}^{L *}$ and $a_{n+1}^{L *}$. These imply

$$
\left(a_{n}^{L *}\right)^{-\gamma}\left(1-\nu \frac{S_{n}^{H}}{S_{n}^{L}}\right) \geq\left(a_{n+1}^{L *}\right)^{-\gamma}\left(1-\nu \frac{S_{n+1}^{H}}{S_{n+1}^{L}}\right) .
$$

Combining (19) and (20) yields

$$
\nu \leq\left(\frac{\frac{1}{S_{n+1}^{H}}-\frac{1}{S_{n}^{H}}}{\frac{1}{S_{n+1}^{L}}-\frac{1}{S_{n}^{L}}}\right) .
$$

Therefore, (19) will only be possible - and $A^{L *}$ can only solve $\left(P_{0}\right)$-when $\nu$ is sufficiently low. For higher $\nu$, there will be some $t$ for which $\nu>\left(\frac{\frac{1}{S_{n+1}^{H}}-\frac{1}{S_{n}^{H}}}{\frac{1}{S_{n+1}^{L}}-\frac{1}{S_{n}^{L}}}\right)$, 
and we will need to solve $\left(P_{0}\right)$ using some other method. This motivates the following definition:

$$
n_{\text {max }}^{*} \equiv \min \left\{\{N\} \cup\left\{n \in\{0, \cdots, N-1\}: \nu \geq\left(\frac{\frac{1}{S_{n+1}^{H}}-\frac{1}{S_{n}^{H}}}{\frac{1}{S_{n+1}^{L}}-\frac{1}{S_{n}^{L}}}\right)\right\}\right\},
$$

so that $n_{\text {max }}^{*}=N$ if and only if (19) is possible. If $n_{\max }^{*}<N$, then we need some other method for solving $\left(P_{0}\right)$. This is is purpose of Algorithm 1.

\section{Algorithm 1}

1. Start with $n=n_{\max }^{*}$.

2. If $n=0$ or if $S_{n-1}^{H}\left(\tilde{c}_{n-1}^{n}\right)^{-\gamma}>S_{n}^{H}\left(\tilde{c}_{n}^{n}\right)^{-\gamma}$, stop, $n^{*}=n$. Otherwise, take $n=n-1$ and repeat step 2 .

Algorithm 1 starts with $n=n_{\max }^{*}$ and solves $\left(\tilde{P}_{n_{\max }^{*}}\right)$ for $\tilde{A}^{n_{\max }^{*}}$. It checks if $H$ types have a (weak) incentive to save at $n_{\max }^{*}-1$ given their optimal consumption pattern when given $\tilde{A}^{n_{\max }^{*}}$-i.e., the consumption vector $\tilde{\Gamma}$ solving (17) defining $\tilde{V}^{H}\left(\tilde{A}_{\text {max }}^{n_{\text {max }}^{*}} ; n_{\max }^{*}\right)$. If not, stop. If so, decrement $n$ and repeat using $n$ instead of $n_{\text {max }}^{*}$, continuing to decrement $n$ until either there is no incentive to save at $n-1$, or until $n=0$.

Our first lemma shows that the date $n_{\text {max }}^{*}$ is the cutoff $n$ between $\nu>$ $\left(\frac{\frac{1}{S_{n+1}^{H}}-\frac{1}{S_{n}^{H}}}{\frac{1}{S_{n+1}^{L}}-\frac{1}{S_{n}^{L}}}\right)$ and $\nu<\left(\frac{\frac{1}{S_{n+1}^{H}}-\frac{1}{S_{n}^{H}}}{\frac{1}{S_{n+1}^{L}}-\frac{1}{S_{n}^{L}}}\right)$. This plays a key role in assuring that the algorithm works correctly.

Lemma 1 For the Gompertz mortality curves we consider, $\left(\frac{\frac{1}{S_{n+1}^{H}}-\frac{1}{S_{n}^{H}}}{\frac{1}{S_{n+1}^{L}}-\frac{1}{S_{n}^{L}}}\right)$ is declining in $n$.

Lemma 1 is easily verified by numerical computations for our particular parametrization of the Gompertz mortality curves. A formal proof of the lemma for any pair of Gompertz mortality curves involves tedious algebra and a limiting argument. It is omitted here but is available upon request from the authors.

Our second lemma characterizes the consumption patterns $\Gamma^{n}=\left(c_{0}^{n}, \cdots, c_{N}^{n}\right)$ which solve (17) for a given solution $A^{n}=\left(a_{0}^{n}, \cdots, a_{N}^{n}\right)$ to $\left(P_{n}\right)$. Note that, by assumption, any such consumption pattern has $c_{t}^{n}=a_{t}^{n}$ for $t \leq t_{0}$. 
Lemma 2 If $A^{n}=\left(a_{0}^{n}, \cdots, a_{N}^{n}\right)$ solves $\left(P_{n}\right)$, and $\Gamma^{n}=\left(c_{0}^{n}, \cdots, c_{N}^{n}\right)$ solves the program defining $V^{H}\left(A^{n} ; n\right)$, then $\exists$ an integer $k \geq 0$ and a set $\mathbb{T}=$ $\left\{t_{0}, \cdots, t_{k}, t_{k+1}\right\}$ of integers $t_{i}$, with $t_{0} \equiv n-1, t_{i}<t_{i+1}$, and $t_{k+1}=N$, such that:

- For $t_{0}<t<t^{\prime}: S_{t}^{H}\left(c_{t}^{n}\right)^{-\gamma} \geq S_{t^{\prime}}^{H}\left(c_{t^{\prime}}^{n}\right)^{-\gamma}$, with equality iff $\exists i$ such that $t_{i}<t$ and $t^{\prime} \leq t_{i+1} ;$ and

- For each $i \leq k$,

$$
\sum_{t=t_{i}+1}^{\bar{t}} \delta^{n}\left(c_{t}^{n}-a_{t}^{n}\right) \leq 0,
$$

for each $t_{i}+1 \leq \bar{t} \leq t_{i+1}$, with equality if $\bar{t}=t_{i+1}$.

Lemma 2 states that the dates after $n-1$ can be broken up, by some set of cutoff values $\mathbb{T}$, into a series of intervals $\left[t_{i}+1, \cdots, t_{i+1}\right]$. Within each interval, $H$ types consume in such a way that they have no incentive to save or borrow. At the upper end $t_{i}$ of an interval, the $H$ type's consumption is such that they have a strict incentive to shift consumption from $t_{i}+1$ back to $t_{i}$; they cannot do so, because they cannot borrow and they do not carry positive wealth between $t_{i}$ and $t_{i}+1$. The "proof" involves simply looking at $C^{n}$ and $A^{n}$ and defining the appropriate set $\mathbb{T}$.

Lemmas 3, through 6 below characterize the cutoff values $\mathbb{T}$ for solutions to $\left(P_{n}\right)$. Specifically, Lemma 3 presents some first order necessary conditions for solving $\left(P_{n}\right)$. Lemma 4 uses these first order conditions to establish some properties of the annuity and consumption streams associated with the solution to $\left(P_{n}\right)$, taking the set of cutoffs $\mathbb{T}$ as given. Lemma 5 establishes that when the solution to $\left(P_{n}\right)$ involves the cutoffs $\mathbb{T}=\{n-1, N\}$, it is also a solution to $\left(\tilde{P}_{n}\right)$. Lemma 6 then uses the properties of Lemmas 3 and 4 to show that the only set $\mathbb{T}$ consistent with solving $\left(P_{n}\right)$ when $n^{*} \leq n \leq n_{\max }^{*}$ is the (minimal) set $\{n-1, N\}$. Together, these will tell us that the solutions to $\left(P_{n^{*}}\right)$ and $\left(\tilde{P}_{n^{*}}\right)$ coincide, which enables us to prove Proposition 1.

Lemma 3 Let $A^{n} \equiv\left(a_{0}^{n}, \cdots, a_{N}^{n}\right)$ solve $\left(P_{n}\right)$, let $\Gamma^{n}=\left(c_{0}^{n}, \cdots, c_{N}^{n}\right)$ solve the program defining $V^{H}\left(A^{n}, n\right)$, and let $\mathbb{T}=\left\{t_{0}, \cdots, t_{k}, t_{k+1}\right\}$ be the associated set of integers from Lemma 2. Let $\mu$ be the Lagrange multiplier associated with the constraint $\left(B C^{\prime}\right)$. Then the following must hold:

$$
\mu=\left(a_{t}^{n}\right)^{-\gamma}-\left(c_{t}^{n}\right)^{-\gamma} \nu \frac{S_{t}^{H}}{S_{t}^{L}}, \quad \forall t \in\{0, \cdots, N\},
$$




$$
\begin{gathered}
a_{t}^{n}=c_{t}^{n}, \quad \forall t<N, \\
S_{t}^{H}\left(c_{t}^{n}\right)^{-\gamma}=S_{t^{\prime}}^{H}\left(c_{t^{\prime}}^{n}\right)^{-\gamma}, \quad \forall t, t^{\prime} \in\left\{t_{i}+1, \cdots, t_{i+1}\right\} \quad \forall i \in\{0, \cdots, k\}, \\
\sum_{t=t_{i}+1}^{t_{i+1}} \delta^{t}\left(c_{t}^{n}-a_{t}^{n}\right)=0, \quad \forall i \in\{0, \cdots, k\} .
\end{gathered}
$$

Proof. Since $\frac{\partial V^{H}\left(A^{n} ; n\right)}{\partial a_{t}^{n}}=S_{t}^{H}\left(c_{t}^{n}\right)^{-\gamma},(23)$ is the first order necessary condition for $a_{t}^{n}$ in $\left(P_{n}\right)$. Conditions $(24)-(26)$ characterize necessary conditions for $\Gamma^{n}$ to solve the program defining $V^{H}\left(A^{n} ; n\right)$. Condition (24) follows from the definition of that program. Both (25) and (26) follow from Lemma 2: (25) states that $H$ type's consumption is such that they have no incentive to borrow or save within an interval and (26) states that individuals do not carry positive wealth from one interval to the next.

By Lemma 3, conditions (23)-(26) are necessary for a solution to $\left(P_{n}\right)$. Lemma 4 shows that for any fixed set of cutoffs $\mathbb{T}$, these four conditions are satisfied only for a unique annuity and consumption pair. The lemma further examines how this unique pair varies with the Lagrange multiplier $\mu$ : since $\mu$ can be interpreted as a marginal utility of resources and $u^{\prime}(x)=x^{-\gamma}$, the pair varies with $\mu$ as $\mu^{-\frac{1}{\gamma}}$.

Lemma 4 Fix $\mu>0$ and $\mathbb{T}$. Then there is a unique annuity and consumption pair, $\left(a_{0}^{\prime n}, \cdots, a_{N}^{\prime n}\right) \equiv A^{\prime n}$ and $\left(c_{0}^{\prime n}, \cdots, c_{N}^{\prime n}\right)=\Gamma^{\prime n}$, that solves (23) through (26). Viewed as a function of $\mu, a_{t}^{\prime n}(\mu)=a_{t}^{\prime n}(1) \mu^{-\frac{1}{\gamma}}$ and $c_{t}^{\prime n}(\mu)=c_{t}^{\prime n}(1) \mu^{-\frac{1}{\gamma}}$.

Proof. Fix a $t_{i}$. Condition (25) determines $\frac{c_{t}^{\prime n}}{c_{t^{\prime}}^{\prime n}}$ for any $t, t^{\prime}$ in the interval $\left[t_{i}+1, \cdots, t_{i+1}\right] .\left(c_{t_{i}+1}^{\prime n}, \cdots, c_{t_{i+1}}^{\prime n}\right)$ is therefore determined up to a scalar multiple. To pin down this scalar multiple, fix a $\tilde{W}_{i} \in \mathbb{R}$ and generate the unique vector $\left(c_{t_{i}+1}^{\prime n}, \cdots, c_{t_{i+1}}^{\prime n}\right)$ consistent with $(25)$ and with $\tilde{W}_{i}=\sum_{t=t_{i}+1}^{t_{i+1}} \delta^{t} c_{t}^{\prime n}$. Next, define the function $M_{1}: \mathbb{R} \rightarrow \mathbb{R}^{t_{i+1}-t_{i}}$ by $M_{1}\left(\bar{a}_{t_{i}+1}^{n}\right) \equiv\left(\bar{a}_{t_{i}+1}^{n}, \cdots, \bar{a}_{t_{i+1}}^{n}\right)$, where $\bar{a}_{t}^{n}$ is defined implicitly via

$$
\left(\bar{a}_{t}^{n}\right)^{-\gamma}-\left(c_{t}^{\prime n}\right)^{-\gamma} \nu \frac{S_{t}^{H}}{S_{t}^{L}}=\left(\bar{a}_{t_{i}+1}^{n}\right)^{-\gamma}-\left(c_{t_{i}+1}^{\prime n}\right)^{-\gamma} \nu \frac{S_{t_{i}+1}^{H}}{S_{t_{i}+1}^{L}},
$$

as required by (23). Similarly, define the function $M_{2}: \mathbb{R}^{t_{i+1}-t_{i}} \rightarrow \mathbb{R}$ via $M_{2}\left(\bar{a}_{t_{i}+1}^{n}, \cdots, \bar{a}_{t_{i+1}}^{n}\right) \equiv \sum_{t=t_{i}}^{t_{i+1}} \delta^{t} \bar{a}_{t}^{n}$. Then $M_{2}\left(M_{1}\left(\bar{a}_{t_{i}+1}\right)\right)$ is strictly increasing 
in $\bar{a}_{t_{i}+1}$; hence there is a unique $\bar{a}_{t_{i}+1}$ such that $M_{2}\left(M_{1}\left(\bar{a}_{t_{i}+1}\right)\right)=\tilde{W}_{i}$. Therefore, for any $\tilde{W}_{i}$, there is a unique pair of vectors $\left(a_{t_{i}+1}^{\prime n}\left(\tilde{W}_{i}\right), \cdots, a_{t_{i+1}}^{\prime n}\left(\tilde{W}_{i}\right)\right)$ and $\left(c_{t_{i}+1}^{\prime n}\left(\tilde{W}_{i}\right), \cdots, c_{t_{i+1}}^{\prime n}\left(\tilde{W}_{i}\right)\right)$ consistent with

$$
\tilde{W}_{i}=\sum_{t=t_{i}+1}^{t_{i+1}} \delta^{t} a_{t}^{\prime n}\left(\tilde{W}_{i}\right)=\sum_{t=t_{i}+1}^{t_{i+1}} \delta^{t} c_{t}^{\prime n}\left(\tilde{W}_{i}\right)
$$

and with

$$
\left(a_{t}^{\prime n}\left(\tilde{W}_{i}\right)\right)^{-\gamma}-\left(c_{t}^{\prime n}\left(\tilde{W}_{i}\right)\right)^{-\gamma} \nu \frac{S_{t}^{H}}{S_{t}^{L}}=\left(a_{t_{i}+1}^{\prime n}\left(\tilde{W}_{i}\right)\right)^{-\gamma}-\left(c_{t_{i}+1}^{\prime n}\left(\tilde{W}_{i}\right)\right)^{-\gamma} \nu \frac{S_{t_{i}+1}^{H}}{S_{t_{i}+1}^{L}}
$$

for all $t \in\left\{t_{i}+1, \cdots, t_{i+1}\right\}$.

Clearly, if $\left\{\left(a_{t}^{\prime n}\left(\tilde{W}_{i}\right)\right)_{t=t_{i}+1}^{t_{i+1}},\left(c_{t}^{\prime n}\left(\tilde{W}_{i}\right)\right)_{t=t_{i}+1}^{t_{i+1}}\right\}$ is the unique pair consistent in this sense with $\tilde{W}_{i}$, then $\left\{\left(\beta a_{t}^{\prime n}\left(\tilde{W}_{i}\right)\right)_{t=t_{i}+1}^{t_{i+1}},\left(\beta c_{t}^{\prime n}\left(\tilde{W}_{i}\right)\right)_{t=t_{i}+1}^{t_{i+1}}\right\}$ is uniquely consistent in this sense with $\beta \tilde{W}_{i}$ for any $\beta>0$. Via $\mu$, (23) then pins down a unique $\tilde{W}_{i}$ and corresponding $\left(a_{t_{i}+1}^{\prime n}\left(\tilde{W}_{i}\right), \cdots, a_{t_{i+1}}^{\prime n}\left(\tilde{W}_{i}\right)\right)$ and $\left(c_{t_{i}+1}^{\prime n}\left(\tilde{W}_{i}\right), \cdots, c_{t_{i+1}}^{\prime n}\left(\tilde{W}_{i}\right)\right)$ consistent with (23), (25) and (26) for the interval $i$, and shows that $c_{t}^{\prime n}$ and $a_{t}^{\prime n}$ vary with $\mu$ as $\mu^{-\frac{1}{\gamma}}$ in this interval.

This argument holds for each $t_{i}$, and hence for each $t \geq n$. For $t<n$, a similar argument using (24) instead of (25) establishes the same uniqueness result, completing the proof.

Lemma 4 shows that there is a unique pair $A^{n}$ and $\Gamma^{n}$ that satisfies the necessary conditions for a given fixed $\mathbb{T}$. That is, for any $\mathbb{T}$ there is a unique "candidate" for solving $\left(P_{n}\right)$. We will now establish two lemmas about this candidate solution. First, Lemma 5 shows that if the candidate associated with cutoffs $\mathbb{T}=\{n-1, N\}$ is indeed a solution to $\left(P_{n}\right)$, then it is also a solution to $\left(\tilde{P}_{n}\right)$. Second, Lemma 6 shows that, when $n^{*} \leq n \leq n_{\text {max }}^{*}$, the candidate for any other $\mathbb{T}=\{n-1, N\}$ cannot solve $\left(P_{n}\right)$ for $\mathbb{T}=\{n-1, N\}$. Together, they imply that the solution to $\left(P_{n^{*}}\right)$ solves $\left(\tilde{P}_{n^{*}}\right)$ as well.

Lemma 5 Consider a solution $A^{n}$ to $\left(P_{n}\right)$ and the corresponding $\Gamma^{n}$ solving (17) defining $V^{H}\left(A^{n} ; n\right)$. If the cutoff values $\mathbb{T}$ given by Lemma 2 at this solution are given by $\mathbb{T}=\{n-1, N\}$, then $A^{n}$ solves $\left(\tilde{P}_{n}\right)$. 
Proof. When $\mathbb{T}=\{n-1, N\}$, Lemma 2 implies that $\Gamma^{n}$ also satisfies the first order conditions associated with the program defining $\tilde{V}^{H}\left(A^{n} ; n\right)$, and therefore solves that program. $A^{n}$ is therefore feasible in $\left(\tilde{P}_{n}\right) .\left(\tilde{P}_{n}\right)$ is a tighter program than $\left(P_{n}\right)$, so $A^{n}$ solves $\left(\tilde{P}_{n}\right)$.

Lemma 6 Assume $n^{*} \leq n \leq n_{\max }^{*}$. Let $A^{\prime n}=\left(a_{0}^{\prime n}, \cdots, a_{N}^{\prime n}\right)$ and $\Gamma^{\prime n}=$ $\left(c_{0}^{\prime n}, \cdots, c_{N}^{\prime n}\right)$ solve $\left(P_{n}\right)$ and the program defining $V^{H}\left(A^{\prime n} ; n\right)$, respectively, and let $\mathbb{T}$ be the associated cutoffs from Lemma 2. Then $\mathbb{T}=\{n-1, N\}$.

Proof. If $\mathbb{T} \neq\{n-1, N\}$, take the largest $t_{k} \in \mathbb{T}$ less than $N$. For $A^{\prime n}$ and $\Gamma^{\prime n}$ to solve $\left(P_{n}\right)$ with cutoffs $\mathbb{T}$ and the program defining $V^{H}\left(A^{\prime n} ; n\right)$, respectively, Lemma 2 requires:

$$
\begin{gathered}
a_{t_{k}}^{\prime n} \leq c_{t_{k}}^{\prime n} \\
\quad \text { and } \\
a_{t_{k}+1}^{\prime n} \geq c_{t_{k}+1}^{\prime n} .
\end{gathered}
$$

First suppose, by way of contradiction, that $t_{k} \geq n_{\max }^{*}$, where $n_{\max }^{*}$ is defined in Algorithm 1. Then combining (27) with the necessary condition (23), we observe:

$$
\left(c_{t_{k}}^{\prime n}\right)^{-\gamma}\left(1-\nu \frac{S_{t_{k}}^{H}}{S_{t_{k}}^{L}}\right) \leq\left(c_{t_{k}+1}^{\prime n}\right)^{-\gamma}\left(1-\nu \frac{S_{t_{k}+1}^{H}}{S_{t_{k}+1}^{L}}\right) .
$$

Lemma 2 also requires:

$$
S_{t_{k}}^{H}\left(c_{t_{k}}^{\prime n}\right)^{-\gamma}>S_{t_{k}+1}^{H}\left(c_{t_{k}+1}^{\prime n}\right)^{-\gamma} .
$$

Combining (28) and (29) yields:

$$
\frac{S_{t_{k}+1}^{H}}{S_{t_{k}}^{H}}\left(1-\nu \frac{S_{t_{k}}^{H}}{S_{t_{k}}^{L}}\right)<\left(1-\nu \frac{S_{t_{k}+1}^{H}}{S_{t_{k}+1}^{L}}\right) \quad \text { or } \quad \nu<\left(\frac{\frac{1}{S_{t_{k}+1}^{H}}-\frac{1}{S_{t_{k}}^{H}}}{\frac{1}{S_{t_{k}+1}^{L}}-\frac{1}{S_{t_{k}}^{L}}}\right) .
$$

This contradicts Lemma 1 when $t_{k} \geq n_{\max }^{*}$ by Lemma 1 .

When $\mathbb{T}=\{n-1, N\}$ at the solution to $\left(P_{n}\right)$, the solutions to $\left(\tilde{P}_{n}\right)$ and $\left(P_{n}\right)$ coincide by Lemma 5 . Having ruled out $t_{k} \geq n_{\text {max }}^{*}$, we conclude that $\left(P_{n_{\text {max }}^{*}}\right)$ is uniquely solved with cutoffs $\mathbb{T}_{n_{\text {max }}^{*}}=\left\{n_{\text {max }}^{*}-1, N\right\}$ and that the solutions to $\left(\tilde{P}_{n_{\text {max }}^{*}}\right)$ and $\left(P_{n_{\text {max }}^{*}}\right)$ coincide. 
Proceeding by induction, suppose that for some $\tilde{n} \geq n^{*},\left(P_{n}\right)$ is uniquely solved with cutoffs $\mathbb{T}_{n}=\{n-1, N\}$ for each $n \geq \tilde{n}+1$. By Lemma 5 , the solutions to $\left(\tilde{P}_{n}\right)$ and $\left(P_{n}\right)$ must then coincide for $n \geq \tilde{n}+1$. We will prove that $\mathbb{T}_{\tilde{n}}=\{\tilde{n}-1, N\}$ by contradiction: suppose there is a solution to $\left(P_{\tilde{n}}\right)$ involving cutoffs $\mathbb{T}=\left\{\tilde{n}-1, \cdots, t_{k}, N\right\} \neq\{\tilde{n}-1, N\}$. From above, $t_{k}<n_{\max }^{*}$ must hold.

Fix $\mu=1$ (without loss of generality by Lemma 4), and take $\Gamma^{\prime \tilde{n}}$ and $A^{\prime \tilde{n}}$ as in Lemma 4 for $n=\tilde{n}$ and cutoffs $\mathbb{T}$. Take $\Gamma^{\prime \prime t_{k}+1}$ and $A^{\prime \prime t_{k}+1}$ as in Lemma 4 for $n=t_{k}+1$ and cutoffs $\left\{t_{k}, N\right\}$; then $\Gamma^{\prime \prime t_{k}+1}=\Gamma^{t_{k}+1}=\tilde{\Gamma}^{t_{k}+1}$ and $A^{\prime \prime t_{k}+1}=A^{t_{k}+1}=\tilde{A}^{t_{k}+1}$ by the inductive hypothesis. By the argument in the proof of Lemma $4, c_{t}^{\prime \tilde{n}}=c_{t}^{\prime \prime t_{k}+1}$ for $t=t_{k}+1, \cdots, N$ : having fixed $\mu$, there is a unique solution within each interval, and the top intervals for the two problems coincide.

By Lemma $2, c_{t_{k}}^{\prime \tilde{n}} \geq a_{t_{k}}^{\prime \tilde{n}}$, whereby $(23)$ yields $\mu \equiv 1 \geq\left(a_{t_{k}}^{\prime \tilde{n}}\right)^{-\gamma}\left(1-\nu \frac{S_{t_{k}}^{H}}{S_{t_{k}}^{L}}\right)$. Similarly, since $a_{t_{k}}^{\prime \prime t_{k}+1}=c_{t_{k}}^{\prime \prime t_{k}+1}$ we conclude that $1=\left(a_{t_{k}}^{\prime \prime t_{k}+1}\right)^{-\gamma}\left(1-\nu \frac{S_{t_{k}}^{H}}{S_{t_{k}}^{L}}\right)$. Therefore, $a_{t_{k}}^{\prime \prime t_{k}+1} \leq a_{t_{k}}^{\prime \tilde{n}}$ and $c_{t_{k}}^{\prime \prime t_{k}+1} \leq c_{t_{k}}^{\prime \tilde{n}}$.

To complete the proof, note that if $A^{\prime n}$ solves $\left(P_{n}\right)$ then Lemma 2 requires $S_{t_{k}}^{H}\left(c_{t_{k}}^{\prime \tilde{n}}\right)^{-\gamma}>S_{t_{k}+1}^{H}\left(c_{t_{k}+1}^{\prime \tilde{n}}\right)^{-\gamma}$. Since $c_{t_{k}}^{\prime \prime t_{k}+1} \leq c_{t_{k}}^{\prime \tilde{n}}$ and $c_{t_{k}+1}^{\prime \prime t_{k}+1}=c_{t_{k}+1}^{\prime \tilde{n}}$, this implies $S_{t_{k}}^{H}\left(c_{t_{k}}^{\prime \prime \prime t_{k}+1}\right)^{-\gamma}>S_{t_{k}+1}^{H}\left(c_{t_{k}+1}^{\prime \prime t_{k}+1}\right)^{-\gamma}$. Noting that $\Gamma^{\prime \prime t_{k}+1}=\Gamma^{t_{k}+1}=\tilde{\Gamma}^{t_{k}+1}$, Algorithm 1 implies $n^{*} \geq t_{k}+1$, since Algorithm 1 would have stopped at $t_{k}+1$, if not before. Since $\tilde{n} \geq n^{*}$ and $\tilde{n} \leq t_{k}$, we have reached our contradiction, completing the proof.

We are now ready to state and prove Proposition 1 . Proposition 1 states that the solution to $\left(\tilde{P}_{n^{*}}\right)$ solves $\left(P_{0}\right)$. This means that $\left(\tilde{P}_{n^{*}}\right)$ can be used to solve $(7)$ in the text - all that is additionally required is a search for the proper value of the multiplier $\nu$. Since $\left(\tilde{P}_{n}\right)$ is easily solved, we will be done once we have proved Proposition 1.

Proposition 1 If $\tilde{A}^{n^{*}}$ solves $\left(P_{n^{*}}\right)$, then $A^{n^{*}}$ solves $\left(P_{0}\right)$ and $\left(\tilde{P}_{n^{*}}\right)$ where $n^{*}$ is the outcome of Algorithm 1.

Proof. A solution $\tilde{A}^{n^{*}}=\left(a_{0}^{n^{*}}, \cdots, a_{N}^{n^{*}}\right)$ to $\left(P_{n^{*}}\right)$ must exist, since the set of $A$ satisfying the constraints is compact and the objective function is continuous. Lemmas 4 and 6 together imply that this solution is unique and involves the cutoff values $\mathbb{T}=\{n-1, N\}$. By Lemma 5 , this solution also solves $\left(\tilde{P}_{n^{*}}\right)$. Examination of the first order conditions shows that this solution to $\left(\tilde{P}_{n^{*}}\right)$ is unique. 
Since $V^{H}(A ; n) \leq V^{H}(A ; 0)$ for every $A$, the value of Program $\left(P_{n^{*}}\right)$ is at least as large as the value of Program $\left(P_{0}\right)$. It therefore suffices to show that $V^{H}\left(\tilde{A}^{n^{*}} ; n^{*}\right)=V^{H}\left(\tilde{A}^{n^{*}} ; 0\right)$. Let $\Gamma^{n^{*}}=\left(c_{0}^{n^{*}}, \cdots, c_{N}^{n^{*}}\right)$ solve the program defining $V^{H}\left(\tilde{A}^{n^{*}} ; n^{*}\right)$. $\Gamma^{n^{*}}$ must also solve the program (18) defining $\tilde{V}^{H}\left(\tilde{A}^{n^{*}} ; n^{*}\right)$, or else $\tilde{A}^{n^{*}}$ couldn't solve both $\left(P_{n}\right)$ and $\left(\tilde{P}_{n}\right)$. We need only to check that $\Gamma^{n^{*}}$ also solves the program (17) defining $V^{H}\left(\tilde{A}^{n^{*}}, 0\right)$. Since (17) is a globally concave program and $\Gamma^{n^{*}}$ satisfies all of the constraints, it suffices to show that $S_{t}^{H}\left(c_{t}^{n^{*}}\right)^{-\gamma} \geq S_{t+1}^{H}\left(c_{t+1}^{n^{*}}\right)^{-\gamma}$ for each $t$, with equality for any $t$ at which $\sum_{s=0}^{t} \delta^{s}\left(c_{s}^{n^{*}}-a_{s}^{n^{*}}\right)<0$.

For $t \geq n^{*}, S_{t}^{H}\left(c_{t}^{n^{*}}\right)^{-\gamma}=S_{t+1}^{H}\left(c_{t+1}^{n^{*}}\right)^{-\gamma}$. This is a necessary condition for $\Gamma^{n^{*}}$ to solve the program defining $\tilde{V}^{H}\left(\tilde{A}^{n^{*}} ; n^{*}\right)$. If $n^{*}=0$, we are done. Otherwise, for $t<n^{*}$, we have $c_{t}^{n^{*}}=a_{t}^{n^{*}}$, so $\sum_{s=0}^{t} \delta^{s}\left(c_{s}^{n^{*}}-a_{s}^{n^{*}}\right)=0$, and we need only verify that $S_{t}^{H}\left(c_{t}^{n^{*}}\right)^{-\gamma} \geq S_{t+1}^{H}\left(c_{t+1}^{n^{*}}\right)^{-\gamma}$. By Algorithm 1, $S_{n^{*}-1}^{H}\left(c_{n^{*}-1}^{n^{*}}\right)^{-\gamma}>S_{n^{*}}^{H}\left(c_{n^{*}}^{n^{*}}\right)^{-\gamma}$. We are therefore done if $n^{*}=1$.

If $n^{*}>1$, suppose, by way of contradiction, that

$$
S_{t}^{H}\left(c_{t}^{n^{*}}\right)^{-\gamma}<S_{t+1}^{H}\left(c_{t+1}^{n^{*}}\right)^{-\gamma}
$$

for some $t<n^{*}-1$. Since $c_{t}^{n^{*}}=a_{t}^{n^{*}}$ for $t<n^{*}$,

$$
\left(a_{t}^{n^{*}}\right)^{-\gamma}\left(1-\nu \frac{S_{t}^{H}}{S_{t}^{L}}\right)=\left(a_{t+1}^{n^{*}}\right)^{-\gamma}\left(1-\nu \frac{S_{t+1}^{H}}{S_{t+1}^{L}}\right)
$$

by Lemma 3. (30) and (31) can be used to show that $\nu>\left(\frac{\frac{1}{S_{t+1}^{H}}-\frac{1}{S_{t}^{H}}}{\frac{1}{S_{t+1}^{L}}-\frac{1}{S_{t}^{L}}}\right)$. But since $t<n^{*} \leq n_{\text {max }}^{*}$, this is impossible given Algorithm 1 and Lemma 1 . This contradiction shows that $S_{t}^{H}\left(c_{t}^{n^{*}}\right)^{-\gamma} \geq S_{t+1}^{H}$ for each $t<n^{*}-1$, which completes our proof. 